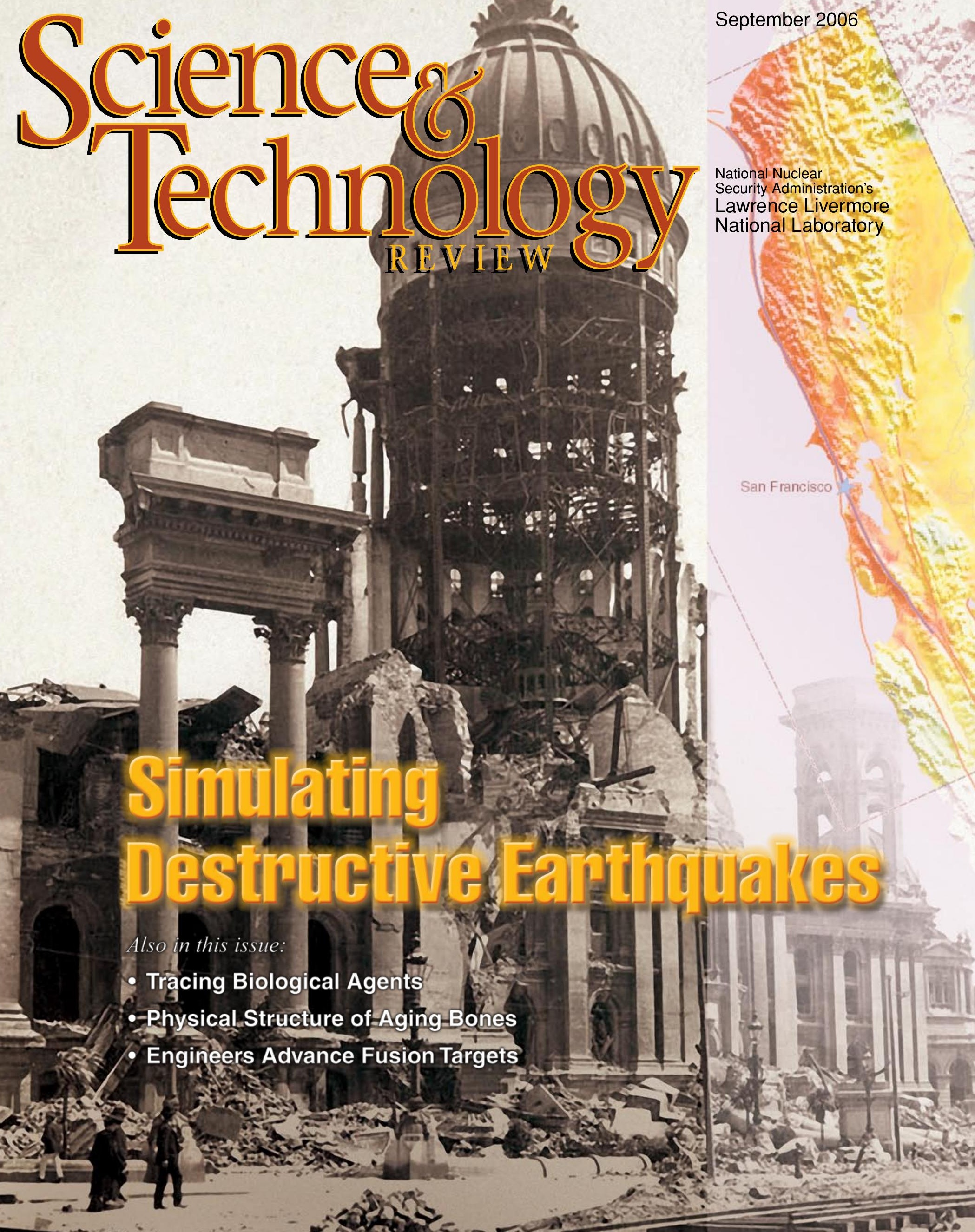




\section{About the Cover}

Livermore has performed supercomputer simulations of the 1906 San Francisco earthquake and is examining future scenarios for earthquakes on several fault lines running through the San Francisco Bay Area. As the article on p. 4 describes, these simulations can help government officials plan for future temblors. The U.S. Geological Survey predicts a 62-percent chance of a magnitude 6.7 or greater temblor occurring in the next 30 years on a major Bay Area fault. On the cover is a photograph of the remains of San Francisco's City Hall following the 1906 earthquake. (Photo courtesy of the Huntington Library.) A Livermore computer simulation of the 1906 earthquake is shown at right.

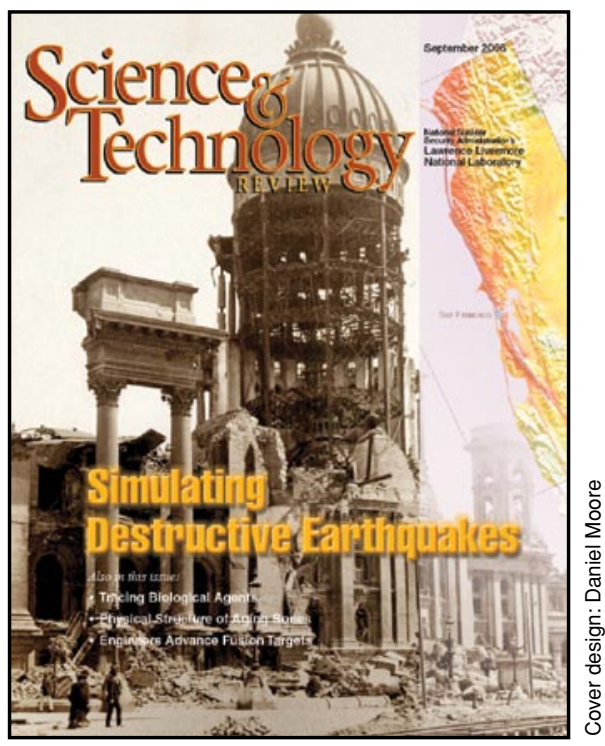

\section{About the Review}

Lawrence Livermore National Laboratory is operated by the University of California for the Department of Energy's National Nuclear Security Administration. At Livermore, we focus science and technology on ensuring our nation's security. We also apply that expertise to solve other important national problems in energy, bioscience, and the environment. Science \& Technology Review is published 10 times a year to communicate, to a broad audience, the Laboratory's scientific and technological accomplishments in fulfilling its primary missions. The publication's goal is to help readers understand these accomplishments and appreciate their value to the individual citizen, the nation, and the world.

Please address any correspondence (including name and address changes) to $S \& T R$, Mail Stop L-664, Lawrence Livermore National Laboratory, P.O. Box 808, Livermore, California 94551, or telephone (925) 423-3432. Our e-mail address is str-mail@llnl.gov. S\&TR is available on the World Wide Web at www.llnl.gov/str.

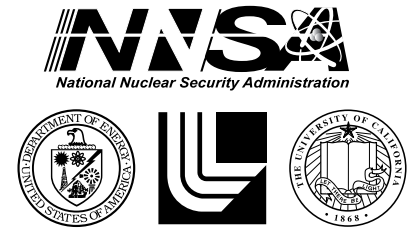

Prepared by LLNL under Contract No. W-7405-Eng-48
(C) 2006. The Regents of the University of California. All rights reserved. This document has been authored by the Regents of the University of California under Contract No. W-7405-Eng-48 with the U.S. Government. To request permission to use any material contained in this document, please submit your request in writing to Library Report Orders, Lawrence Livermore National Laboratory, Mail Stop L-610, P.O. Box 808, Livermore, California 94551, or to our e-mail address report-orders@1lnl.gov.

This document was prepared as an account of work sponsored by an agency of the United States Government. Neither the United States Government nor the University of California nor any of their employees makes any warranty, expressed or implied, or assumes any legal liability or responsibility for the accuracy, completeness, or usefulness of any information, apparatus, product, or process disclosed, or represents that its use would not infringe privately owned rights. Reference herein to any specific commercial product, process, or service by trade name, trademark, manufacturer, or otherwise, does not necessarily constitute or imply its endorsement, recommendation, or favoring by the United States Government or the University of California. The views and opinions of authors expressed herein do not necessarily state or reflect those of the United States Government or the University of California and shall not be used for advertising or product endorsement purposes. 


\section{Science $_{\text {Te }}$ Technogy}

\section{S\&TR Staff}

SCIENTIFIC EDITOR

Harry B. Radousky

Managing Editor

Ray Marazzi

Publichtion Editor

Pamela MacGregor

\section{WrITERS}

Arnie Heller, Ann Parker, Gabriele

Rennie, and Katie Walter

\section{Art Director and Designer}

Daniel Moore

\section{CoMpositor}

Louisa Cardoza

\section{Proofreader}

Carolin Middleton

$S \& T R$, a Director's Office publication, is produced by the Technical Information Department under the direction of the Office of Policy, Planning, and Special Studies.

$S \& T R$ is available on the Web at www.llnl.gov/str.

Printed in the United States of America

\section{Available from}

National Technical Information Service U.S. Department of Commerce

5285 Port Royal Road

Springfield, Virginia 22161

\section{UCRL-TR-52000-06-9}

Distribution Category UC-99

September 2006

\section{Contents}

\section{Features}

3 Simulations Help Plan for Large Earthquakes

Commentary by Jane C. S. Long

4 Re-creating the 1906 San Francisco Earthquake

Supercomputer simulations of Bay Area earthquakes are providing insight into the great 1906 quake and future temblors along several faults.

13 Decoding the Origin of a Bioagent

The microstructure of a bacterial organism can be linked to the methods used to formulate the pathogen.

\section{Research Highlights}

A New Look at How Aging Bones Fracture Livermore scientists find that the increased risk of fracture from osteoporosis may be due to a change in the physical structure of trabecular bone.

\section{Fusion Targets on the Double}

Advances in precision manufacturing allow the production of double-shell fusion targets with submicrometer tolerances.

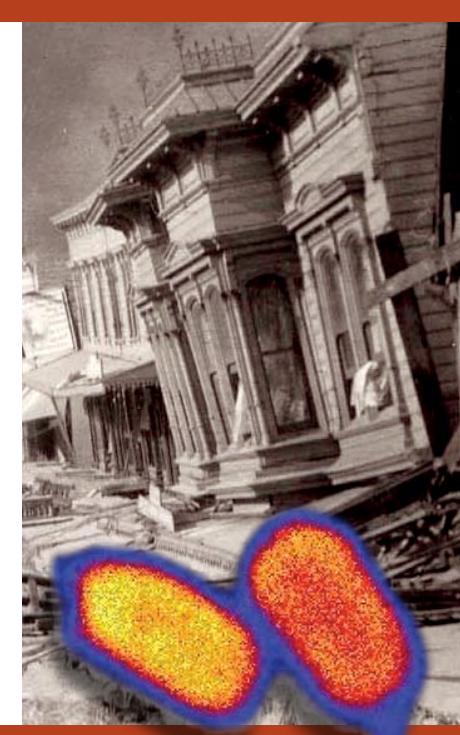

\section{Departments}

2 The Laboratory in the News

27 Patents and Awards

\section{Abstracts}




\section{Lab captures a record seven R\&D 100 awards}

Livermore researchers garnered seven R\&D 100 awards this year. Each year, $R \& D$ Magazine presents these awards to the top 100 industrial, high-technology inventions submitted to its competition for outstanding achievements in research and development.

The seven Livermore inventions honored are as follows:

- Sonoma Persistent Surveillance System, an end-to-end systems approach to monitoring a large field of view 24/7 with sufficient resolution and frame rate to track all moving vehicles in the field.

- UltraSpec, an ultrahigh-resolution gamma and neutron spectrometer that can be configured to characterize and identify gamma-ray or neutron sources.

- Babel, a high-performance language interoperability tool that enables software pieces written in different programming languages to seamlessly call each other.

- E.L.I.T.E. ${ }^{\text {TM }}$, a pocket-sized trace explosives test that is robust, sensitive, cheap, and simple enough to be used by security forces everywhere.

- Sapphire Scientific Data-Mining Software, a software toolkit for analyzing massive, complex data sets arising from scientific experiments, observations, and computer simulations.

- Externally Dispersed Interferometry, a novel interferometerspectrograph system used to measure precision Doppler velocities of stars or sunlit targets.

- High-Average-Power Wavelength Converter, a device for efficiently changing the "color" of laser light, enabling largeaperture, high-average-power lasers to operate at wavelengths different than the wavelength set by the laser medium.

$S \& T R$ 's October issue will feature short articles on these awardwinning inventions and the teams that created them.

Contact: Karena McKinley (925) 423-9353 (mckinley3@IInl.gov).

\section{Nanotube membranes may reduce desalinization costs}

A team of researchers from Lawrence Livermore and the University of California at Berkeley has created a membrane made of carbon nanotubes and silicon that may offer a less expensive way to remove salt from water. The nanotube membranes are more permeable than conventional membranes used in reverse osmosis and could reduce the energy costs of desalination by up to 75 percent.

The permeable membrane is composed of carbon nanotube pore holes on a silicon chip. The nanotubes are hollow and more than 50,000 times thinner than a human hair. Billions of these tubes act as membrane pores. The extremely smooth inside of the nanotubes allows liquids and gases to rapidly flow through, while the tiny pore size blocks larger molecules. The gaps between the aligned carbon nanotubes are filled with a ceramic matrix material. "The gas and water flows that we measured are 100 to 10,000 times faster than what classical models predict," says Livermore physicist and team leader Olgica Bakajin. Another potential application of the membranes is gas separation. The team's research appeared in the May 19, 2006, issue of Science.

\section{Contact: Olgica Bakajin (925) 422-0931 (bakajin1@IInl.gov) or Aleksandr Noy (925) 424-6203 (noy1@IInl.gov).}

\section{Scientists tackle long-standing questions about plutonium}

Plutonium behaves like no other element in nature. In metallic form, its crystal structure is uneven, similar to that of a mineral. In addition, its nucleus is unstable, which causes the metal to spontaneously decay over time and damage the surrounding metal lattice. When the first batches of the metal were made during the Manhattan Project, scientists found the metal too brittle to machine because of the minerallike structure of the crystal. Scientists then added aluminum and found they could retain the ductile facecentered-cubic, or delta, phase. Shortly thereafter, they discovered that gallium also worked to stabilize the delta phase of plutonium, but scientists have not understood why for 60 years. Recently, a team of researchers from Livermore and Carnegie Mellon University has added to the understanding of why gallium is effective.

According to lead researcher Kevin Moore in Livermore's Chemistry and Materials Science Directorate, the metal has a high propensity to adopt a low-symmetry structure because the bonds between plutonium atoms are uneven. However, when a gallium atom is put in the plutonium lattice, the bonds become more uniform, leading to a high-symmetry cubic structure.

"Previous experiments tell us that the plutonium lattice exhibits very slight distortions, but there was no clear explanation as to why this happens," says Moore. "Our calculations explain the observations. They show the distortions are the response of plutonium and its uneven bonds to defects produced in the crystal. The calculations strongly illuminate why gallium stabilizes the ductile cubic structure to room temperature."

The work of Moore, Livermore colleagues Per Söderlind and Adam Schwartz, and David Laughlin of Carnegie Mellon appeared in the May 26, 2006, online edition of Physical Review Letters.

Contact: Kevin Moore (925) 422-9741 (moore78@IInl.gov).

\section{Study shows sperm genetic quality declines with age}

A study led by scientists at Lawrence Livermore and the University of California at Berkeley indicates that the genetic quality of sperm worsens as men get older, increasing a man's risk of being infertile, fathering unsuccessful pregnancies, and passing along dwarfism and possibly other genetic diseases to his children. 


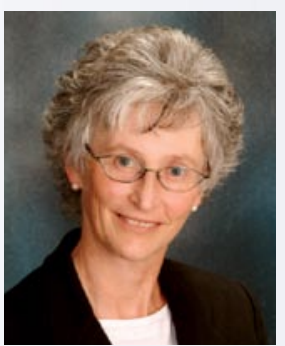

Simulations Her
Earthquakes

AWRENCE Livermore is one of only a few institutions with the expertise and computational resources to advance the scientific understanding of earthquakes through supercomputer simulations. These simulations have become increasingly useful for explaining the destructive forces of past earthquakes and predicting the likely consequences of future ones. To perform this work, the Laboratory combines the talents of applied mathematicians to develop numerical methods, computer scientists to develop codes, the Livermore Computing Center to run the codes on high-performance (parallel processing) computers, earth scientists to build and evaluate geologic models, seismologists to interpret results, and engineers to evaluate the response of structures to ground motion.

Simulating San Francisco Bay Area earthquakes is not a trivial task. Researchers build a grid of billions of computational nodes that are spaced about 100 meters apart to model an area 650 kilometers long by 350 kilometers wide by 50 kilometers deep. This area extends roughly from Big Sur in the south to Crescent City in the north and from the Farallon Islands in the west to the Sierra Foothills in the east. Livermore scientists begin with a model of the Bay Area's geology developed by one of our research partners, the U.S. Geological Survey (USGS). Then they use advanced supercomputer codes developed either here or in conjunction with our colleagues at other research centers. These codes require an enormous amount of computational horsepower; one earthquake simulation used 1,024 microprocessors running together nonstop for 24 hours. The microprocessors recalculated motion at each node every 10 milliseconds.

Livermore's high-resolution earthquake simulations, described in the article beginning on p. 4, provide the predictive capability to understand the effects of ground motion on buildings, transportation systems, and critical infrastructure. The simulations show the widespread effects of a repeat of the 1906 earthquake along the San Andreas Fault. It is important to note the consequences of environmental catastrophes that are exacerbated by increased population. The population of the greater Bay Area (19 counties) is currently about 10 times the population of 1906. If the magnitude 7.9 earthquake that occurred in 1906 were to occur today, the consequences would be devastating. A report on estimates of loss due to a repeat of the 1906 San Francisco earthquake predicts between 800 and 3,400 deaths depending on the time of day; property losses of
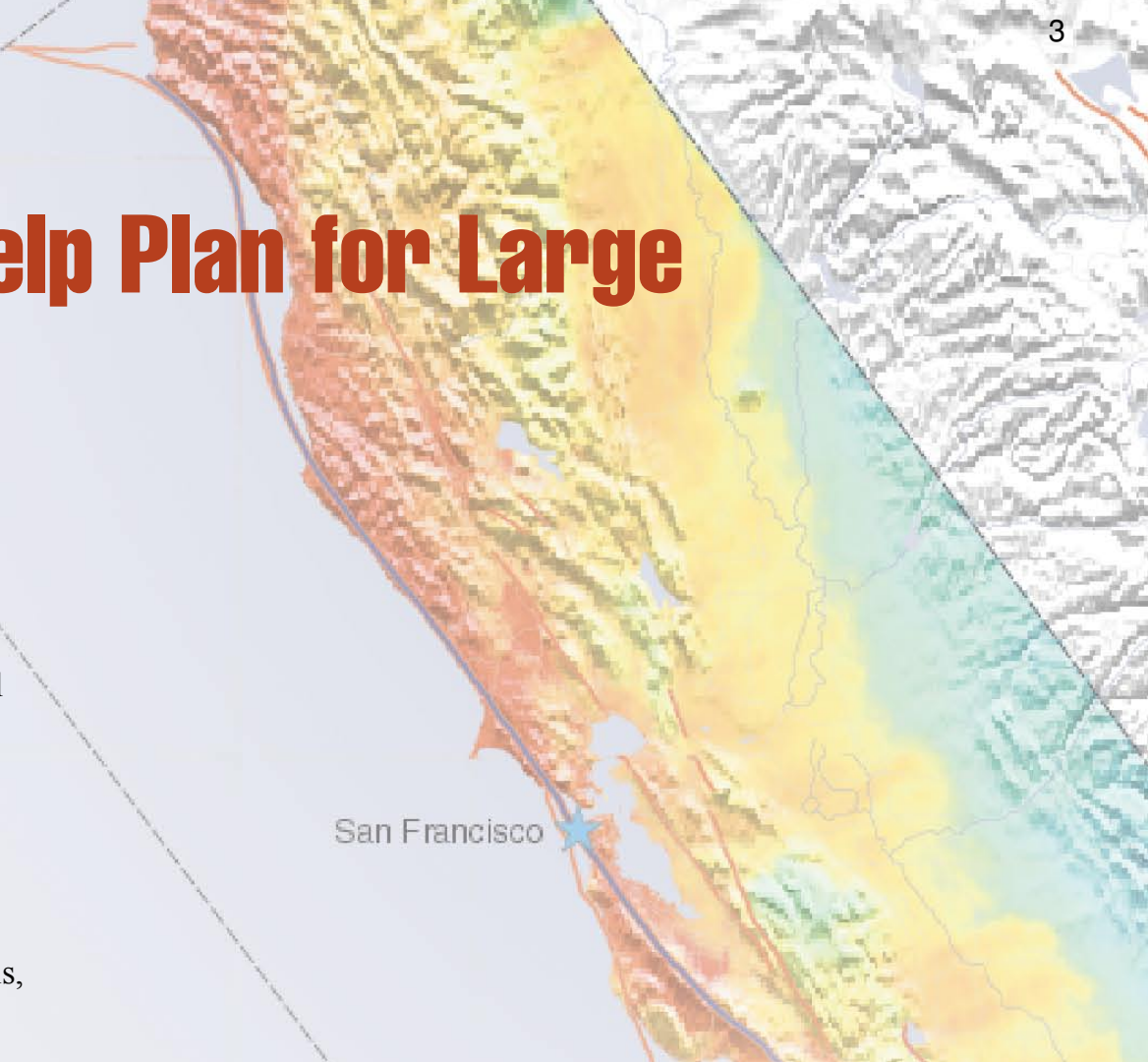

$\$ 90$ to $\$ 120$ billion; 7,000 to 10,000 commercial buildings closed due to damage; and 160,000 to 250,000 households displaced. This disaster would be of similar magnitude as that of Hurricane Katrina in the Gulf Coast region, where estimated losses are between $\$ 100$ and $\$ 150$ billion.

According to USGS, the Hayward-Rodgers Creek Fault is the most likely source of the next large Bay Area earthquake, with a 27-percent chance of a magnitude 6.7 or greater earthquake between now and 2032. This fault has not had a major rupture since 1868. Numerous hospitals and schools are in close proximity to the Hayward-Rodgers Creek Fault. A recent study has indicated that many of these facilities need seismic strengthening. Our simulations also point to the vulnerability of the Sacramento Delta region to seismic shaking by a major earthquake occurring on one of several Bay Area fault lines. The region is protected by a network of largely unreinforced levees. Failure of these levees would threaten the quality and adequate supply of drinking water for millions of California households.

The research on the seismic faults that riddle the Bay Area, and the earthquakes they can trigger, is particularly significant to the Laboratory. Lawrence Livermore employees and their families and communities might be greatly affected by the next large Bay Area earthquake. Much of the Laboratory's workforce crosses one or more faults during their daily commute. Our scientists have an important role to play in helping local, state, and federal authorities plan for the inevitable.

Jane C. S. Long is associate director for Energy and Environment. 


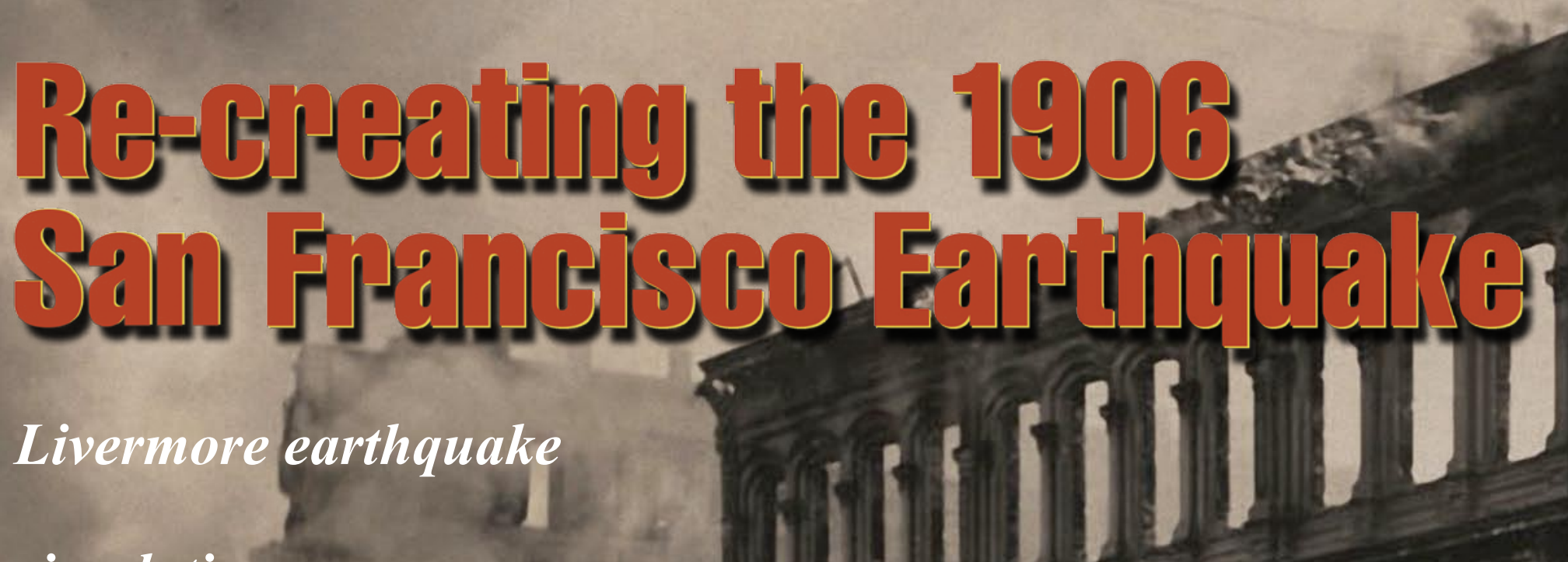

\section{simulations are}

providing insight into

\section{historic and future}

temblors.

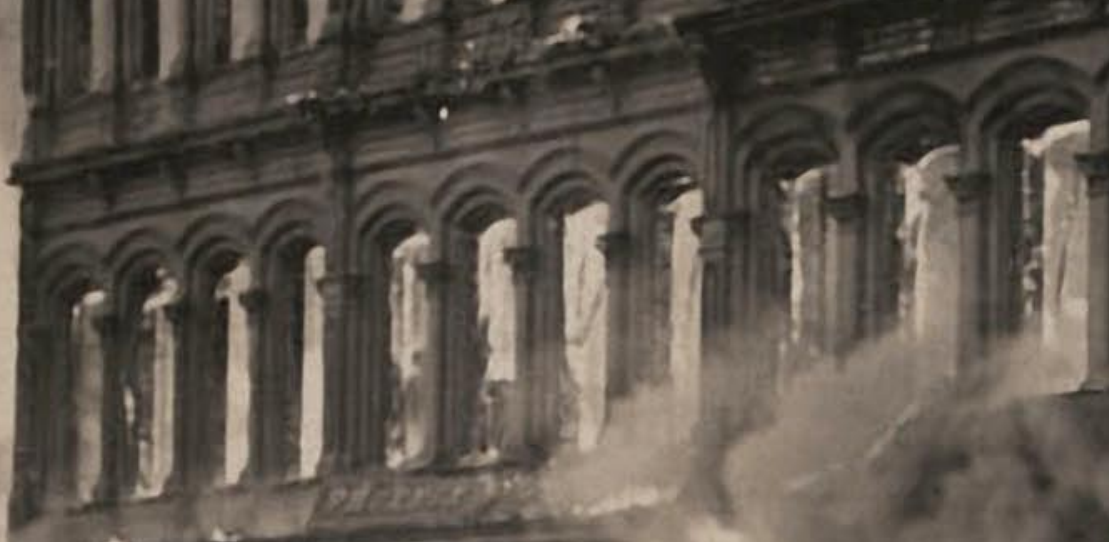




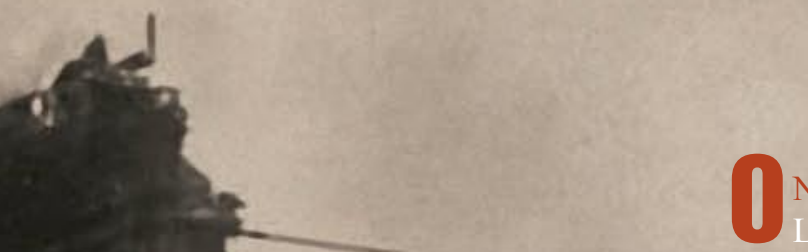

N April 18, 2006, Lawrence in a regional commemoration in San Francisco marking the centennial of the most significant event in the city's history, the great 1906 earthquake. The Livermore scientists, together with colleagues from several research institutions, revealed to state and federal officials and the public the most accurate simulations of the 1906 quake ever conducted. They also shared supercomputer simulations of possible future temblors along other San Francisco Bay Area faults.

"By using advanced simulations to re-create the 1906 earthquake, we get a closer look at how the ground throughout the Bay Area responds to seismic waves," says seismologist Arthur Rodgers, leader of Livermore's seismology group in the Energy and Environment Directorate. "The simulations also allow us to gain insight into what might happen if the San Andreas or other fault lines in the Bay Area were to rupture."

Rodgers, geophysicist and computer scientist Shawn Larsen, applied mathematician Anders Petersson, and other Livermore researchers joined scientists from the University of California at Berkeley (UCB), Stanford University, and URS Corporation (a worldwide engineering firm) in a two-year study coordinated by the U.S. Geological Survey (USGS). The study's goals were to simulate ground motions generated by the 1906 event, compare the results with observations and seismograms recorded at the time, and examine future earthquake scenarios throughout the Bay Area.

The Bay Area has a high density of active faults. Besides the San Andreas, fault zones include Calaveras, Concord- 
The 1906 San Francisco earthquake destroyed more than 28,000 buildings. Looking north along Valencia Street are a sink hole (foreground) and the sunken Valencia Street Hotel (left). (Photo courtesy of the Bancroft Library, University of California, Berkeley.)

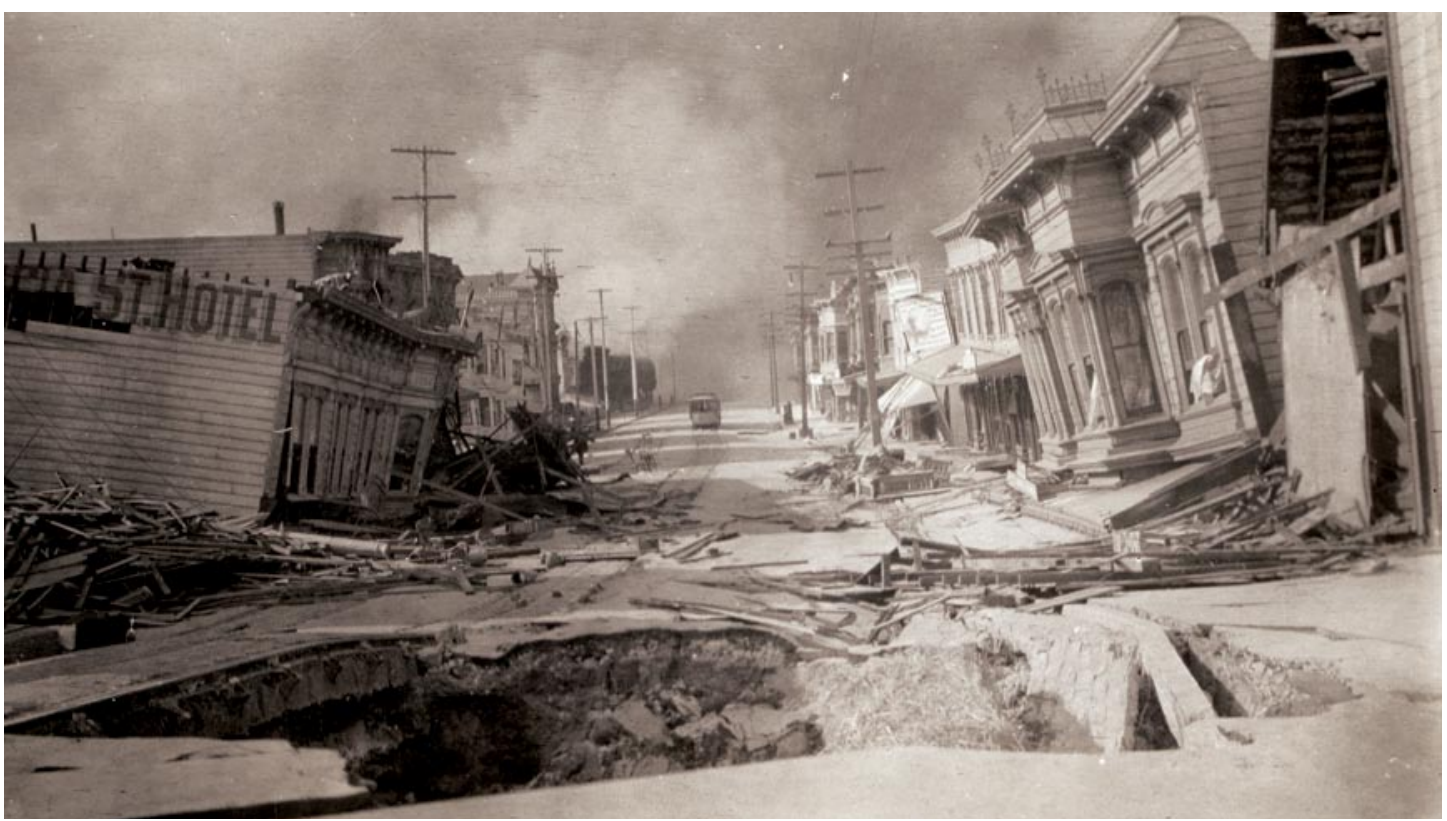

Green Valley, Greenville, HaywardRodgers Creek, and San Gregorio. Together, these faults form a network of parallel fault lines marking where the North American and Pacific plates are slowly pushing against each other. By far the largest fault is the 1,300-kilometer-long San Andreas.

\section{Quake Measured 7.8}

Just before 5:12 a.m. on April 18, 1906, a magnitude 4.0 foreshock on the San Andreas Fault quietly rumbled throughout the Bay Area. About 20 seconds later, a magnitude 7.8 to 7.9 temblor began to rupture, with its epicenter below the Pacific Ocean, just 3 kilometers west of Ocean Beach, San Francisco. Violent shaking swept throughout the entire region and included 17 serious aftershocks within 1 hour.

The quake ruptured 477 kilometers of the San Andreas Fault between San Juan Bautista to the south and Cape Mendocino to the north. (By comparison, the Bay Area's 1989 Loma Prieta earthquake had a rupture length of only about 35 kilometers and one-thirtieth the energy.) The rupture propagated up to 5 kilometers per second.
The amount of horizontal displacement between the Pacific and North American plates varied from 0.5 to 9.7 meters. The earthquake was felt from southern Oregon to Los Angeles and inland as far east as central Nevada.

Kevin Starr, professor of history at the University of Southern California and California State librarian emeritus, described the earthquake during a presentation to Lawrence Livermore employees last April. He termed the quake "one of the greatest catastrophes in U.S. urban areas." In all, more than 28,000 buildings were destroyed, many of them unreinforced structures that collapsed instantly. From a population of about 400,000 , the earthquake killed approximately 3,000 people and left 225,000 homeless.

The earthquake triggered fires that raged for three days. Because the local police and fire departments were in disarray, U.S. Army General Frederick Funston took control of the firefighting effort, despite no firefighting experience. Using dynamite, black powder, and artillery, the Army blew up many buildings in an attempt to create firebreaks. Starr noted the general population behaved admirably, moving in long lines toward parks and open areas as they dragged their trunks of belongings behind them.

\section{Seismic Waves to Mendocino}

In re-creating the 1906 quake, simulations show seismic waves spreading south for 54 seconds and north for 90 seconds. First, primary waves, which are similar to sound waves, deliver a jolt. They are followed by even more violent secondary waves. The simulations shown in the figures on p. 7 use color to denote the intensity of shaking, with warmer colors indicating stronger ground motion.

The first simulation replicates the 1906 earthquake. Strong ground motion is shown in parts of San Francisco built on fill and, despite their distance from the epicenter, in basins located in the Napa, Sonoma, Santa Clara, Central, San Ramon, and Livermore valleys, as well as the Sacramento-San Joaquin Delta and Santa Rosa.

The second simulation shows a hypothetical magnitude 7.8 earthquake along the San Andreas Fault that begins in the north and ruptures to the south. 
"Although the epicenter for the 1906 earthquake was just west of San Francisco, the ground shaking in San Francisco was relatively mild," says Larsen. "However, if the earthquake had begun north near Cape Mendocino, the shaking would have been much more extreme in San Francisco. In this case, a buildup of seismic energy would have slammed into the Bay Area. In some sense, this phenomenon is counterintuitive. Ground motion can be greater when the epicenter is farther away."

The Livermore simulations were performed using the Laboratory's MCR and Thunder supercomputers and Japan's
Earth Simulator. All are massively parallel machines, in which thousands of microprocessors work together on small parts of enormous numerical problems. Typical simulations involve grids with billions of computational points averaging 100 meters in resolution and encompassing nearly all of northern California.

The Livermore team used several codes that are optimized to run on massively parallel supercomputers. The codes incorporate three-dimensional (3D) information about the propagation of seismic waves, such as how they radiate from an earthquake's source to the surface, at what velocities they propagate, and how they interact with the geology. The codes use a 3D geologic structure model of northern California developed by USGS. The 3D structure of Earth determines when and how strongly an earthquake is felt at particular locations because seismic waves travel differently through different rock types.

The USGS model comprises irregularly shaped blocks, bounded by faults, that stretch 45 kilometers deep, 650 kilometers north to south, and 330 kilometers east to west. (See the top figure on p. 8.) The model also includes the subsurface shape (a)

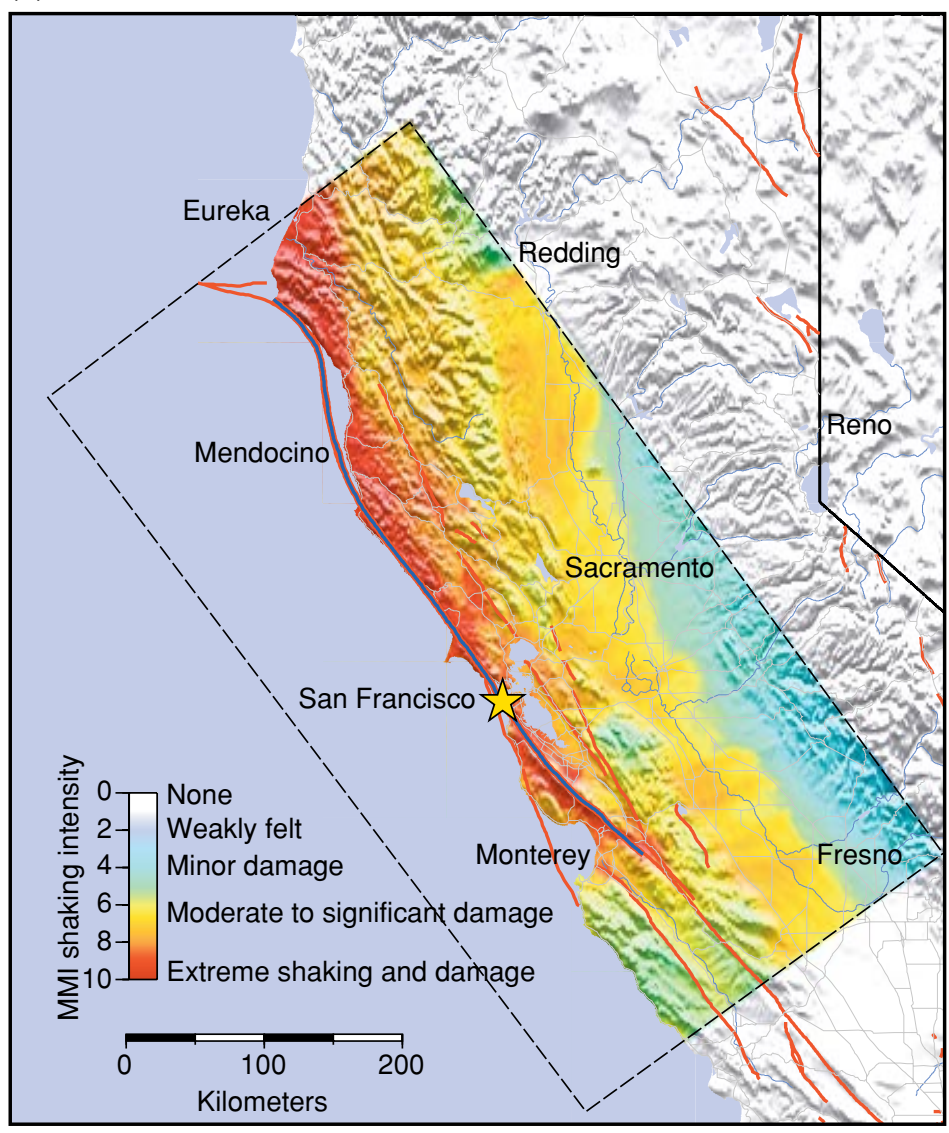

(b)

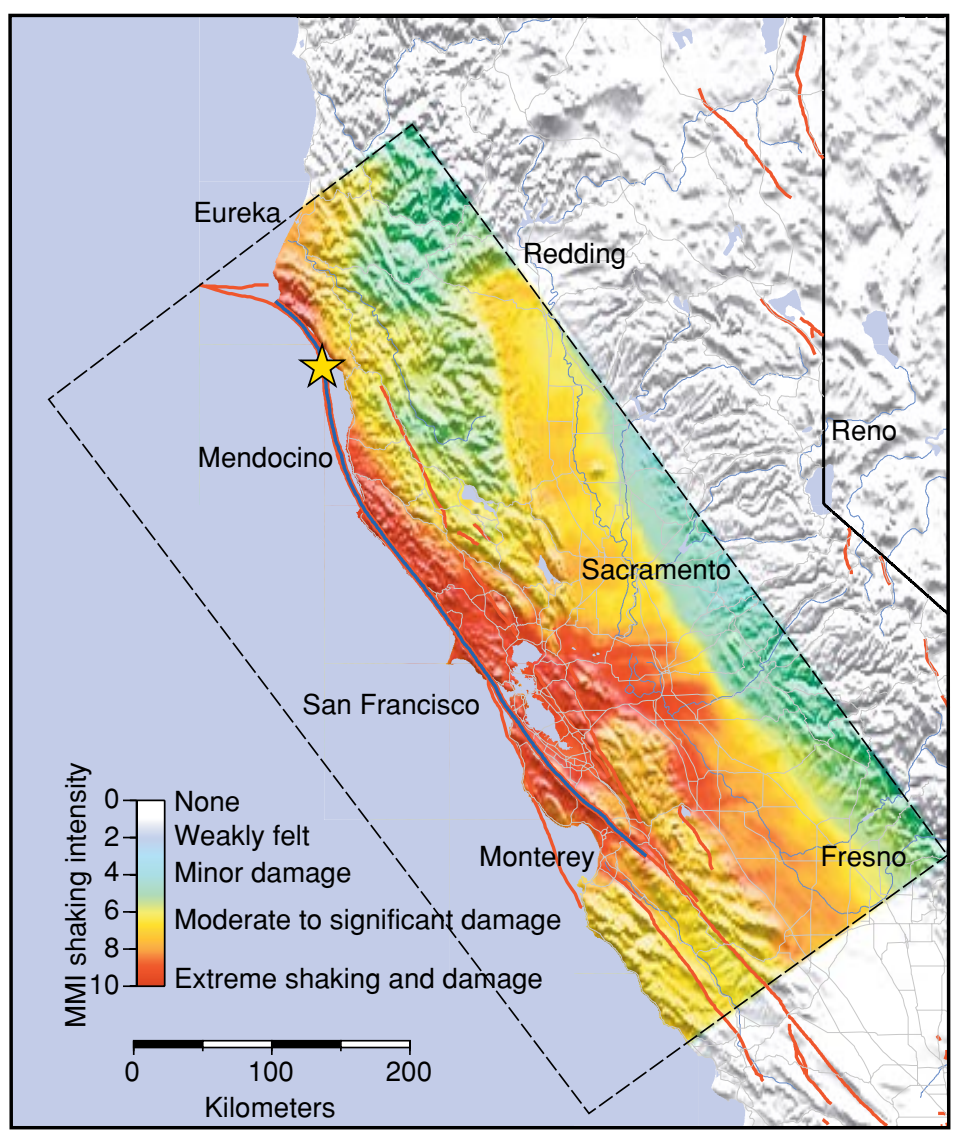

The modified Mercalli intensity (MMI) scale is used to depict shaking severity in two magnitude 7.8 earthquake simulations. (a) One simulation shows the perceived shaking experienced from Eureka to Fresno during the 1906 San Francisco earthquake, with the historical epicenter (denoted by the star) located about 3 kilometers off the coast, along the San Andreas Fault. (b) Another simulation shows a hypothetical magnitude 7.8 earthquake that starts near Cape Mendocino in the north and ruptures to the south. Although the epicenter is farther away, the shaking experienced in San Francisco and in the SacramentoSan Joaquin Delta and Central Valley regions is much greater. 


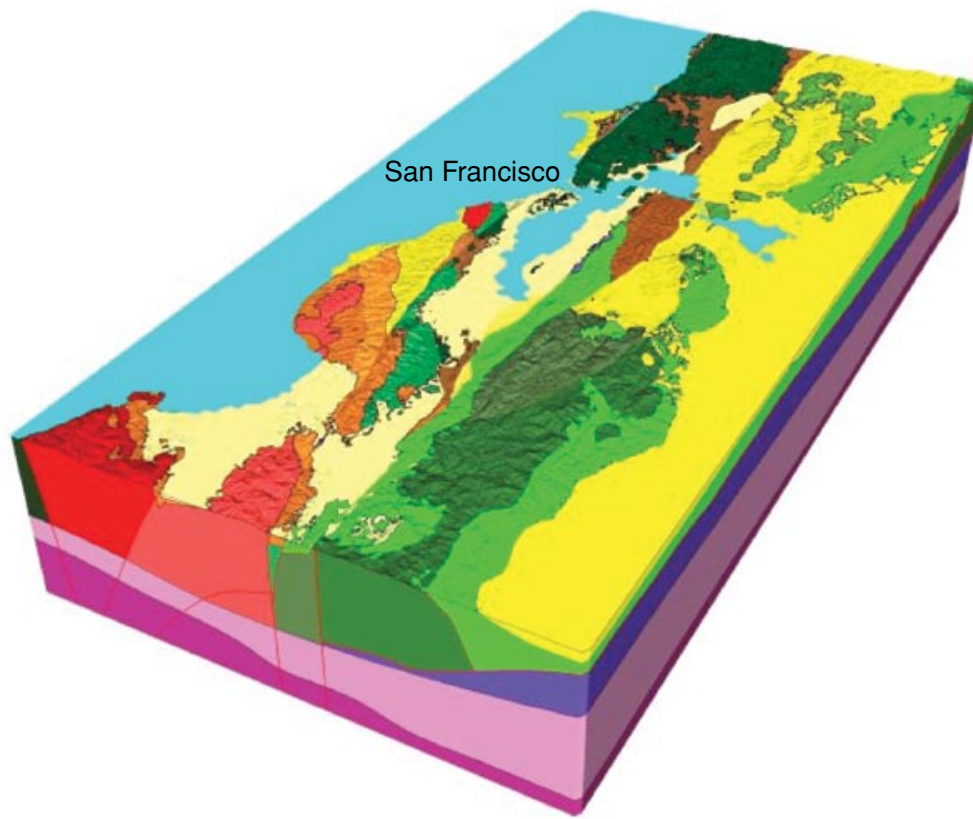

Livermore earthquake simulations use this three-dimensional (3D) geologic structure model for northern California developed by the U.S. Geological Survey (USGS). The 3D structure of Earth affects how strongly an earthquake is felt at different locations. The USGS model comprises irregularly shaped blocks that are bounded by faults.
- Water

Unconsolidated to semiconsolidated Plio-Quaternary deposits

Tertiary sedimentary and local volcanic rocks

Cenozoic deposits, undivided

- Cretaceous and Jurassic forearc sedimentary rocks

Salinian Cretaceous granitic rocks and associated Sur Series metamorphic rocks

Mostly cretaceous and Jurassic subduction-related Franciscan Complex rocks

Jurassic ophiolitic rocks

Matic lower crust Mantle and depth of the basins in underlying areas such as the Santa Clara Valley. The new 3D model was used in simulations of the 1906 earthquake, the 1989 Loma Prieta earthquake, and potential future Bay Area earthquakes on various faults. (See additional simulations at http://earthquake. usgs.gov/1906/simulations.)

\section{Codes Make It Possible}

Rodgers and Petersson used a code called Wave Propagation Program (WPP) for their simulations. The code, which was developed by Petersson and coworkers with funding from Livermore's Laboratory Directed Research and Development Program, takes advantage of advanced numerical methods for creating earthquake simulations and generates "synthetic" seismograms from selected locations around the Bay Area. "The WPP methodology incorporates everything we need for advanced simulations of seismic waves," says Rodgers.

Working with Jeroen Tromp at the California Institute of Technology, Rodgers also used a spectral element method (SEM)

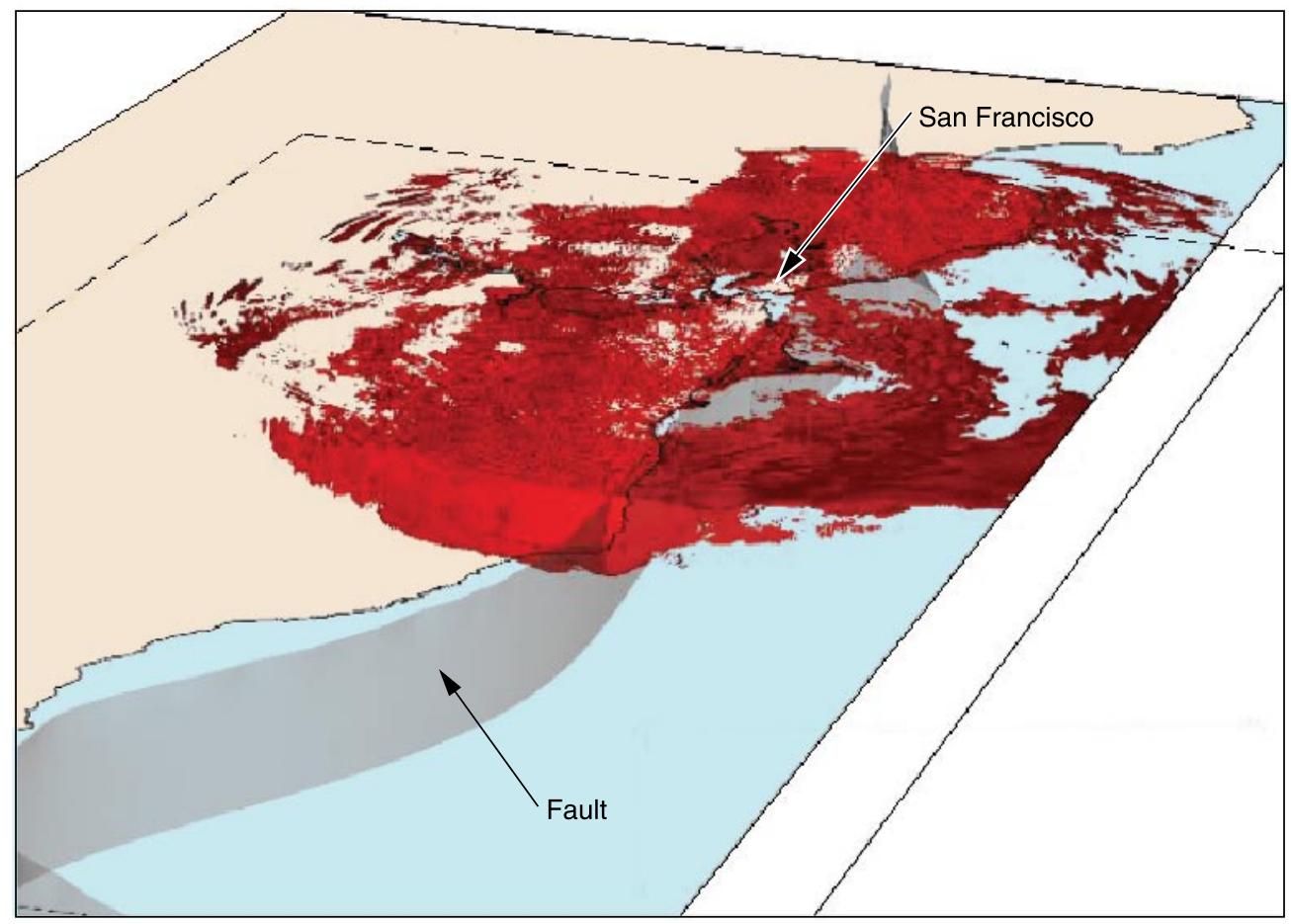

This 3D rendering taken from a Livermore simulation of the 1906 San Francisco earthquake shows the 12-kilometer-deep San Andreas Fault (gray ribbon) in the process of rupturing. The observer is looking at the greater Bay Area from north to south, with the rupture advancing northward. This simulation was performed using the Wave Propagation Program code. 
code to simulate the 1906 San Francisco earthquake. Rodgers explains that most codes treat the geographic areas that they are simulating like flat maps. The SEM code, however, models the globe in spherical coordinates by dividing it into curved sections.

Larsen used the E3D code for his simulations. Although Larsen developed the code nearly 15 years ago, he has continued to modify it to take advantage of supercomputer advances. E3D was previously used to simulate earthquakes on the Hayward-Rodgers Creek Fault and determine the potential effects of such quakes on the San Francisco-Oakland Bay Bridge. (See $S \& T R$, December 1998, pp. 18-20; October 2001, pp. 4-12.) The code has an extensive user base at other national laboratories and in government agencies, academia, and industry. Larsen, together with Doug Dreger and David Dolenc at UCB, also used CODE3, a wave propagation package available in the public domain. CODE3 is the result of a combined effort at several U.S. universities and firms.

\section{Predicting Future Temblors}

One important use of these simulation codes is to help Bay Area government officials plan for future earthquakes. In the last half of the 1800 s, earthquakes of magnitude 6.0 or greater occurred in the Bay Area at an average rate of once every four years. Seismicity rates dropped sharply after the 1906 earthquake. Scientists believe the 1906 earthquake relieved stresses on faults throughout the Bay Area.

The level of seismic activity has not yet returned to that of the late $1800 \mathrm{~s}$. The stresses continue to build and now the risk is high for another great quake in the Bay Area. USGS predicts a 62-percent chance of a magnitude 6.7 or greater temblor occurring in the next 30 years on a major Bay Area fault. The fault with the highest probability of slipping in the next 30 years is the 90-kilometer-long Hayward-Rodgers Creek Fault, with a 27-percent chance of a quake of magnitude 6.7 or greater.
When May Lou Zoback, coordinator of the USGS earthquake hazards team, spoke to Livermore employees in April 2006, she warned that the Hayward-Rodgers Creek Fault has had a magnitude 6.5 or greater earthquake every 150 years (give or take 25 years) over the past several centuries.
The last one, a magnitude 7.0, occurred in 1868. It was known as the "Great San Francisco Earthquake" prior to 1906.

"You do the math, and you can see why we're really worried about this fault," said Zoback. An estimated 160,000 households would be displaced if a major earthquake

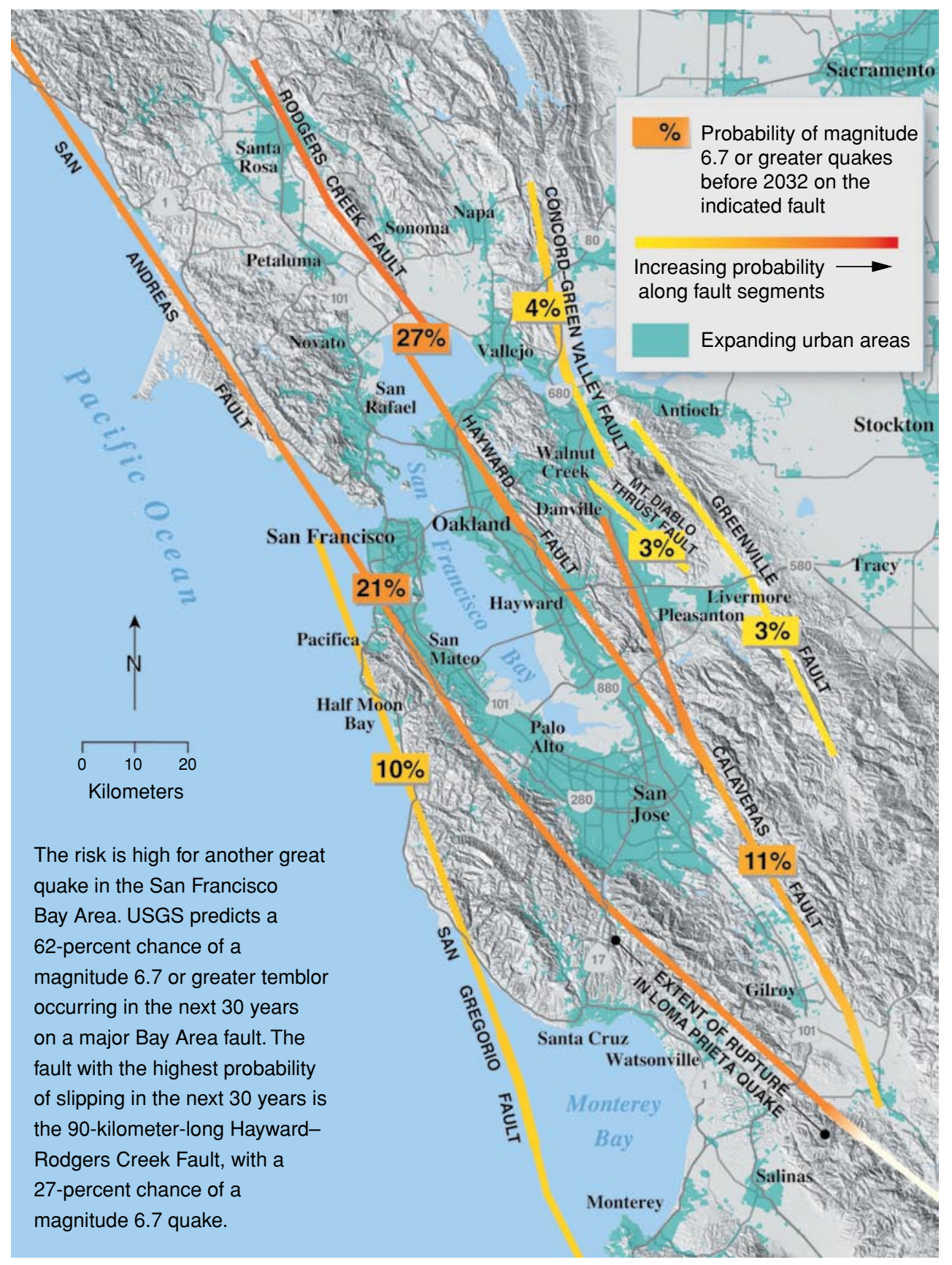


erupts on the Hayward-Rodgers Creek Fault, according to Zoback. The Livermore team has done a number of earthquake simulations of the Hayward-Rodgers Creek Fault, which Larsen calls "the most dangerous fault in the U.S." Simulations of a magnitude 6.7 quake on this fault show shaking to be almost as strong in the East Bay as it was from the much stronger 1906 quake centered on the San Andreas.

Rodgers notes that the intensity of shaking that an area experiences during an earthquake depends on the magnitude of the earthquake, its distance from the fault, and its type of ground materials. Soft, watersaturated sands and sediments amplify the shaking, while bedrock shakes less, which is why seismologists are so concerned about the possible effects to the Sacramento-San Joaquin Delta from a future strong quake on the San Andreas, Hayward-Rodgers Creek, or Greenville faults. "Simulations show more shaking in the delta area than we expected," says Larsen.

The delta covers 738,000 acres of reclaimed marshland protected by 1,100 miles of earthen levees, many built more than a century ago. "The delta levees are prone to liquefaction, a phenomenon that occurs when water-saturated material is subjected to shaking," says Rodgers. During liquefaction, the ground loses its strength, which can cause buildings to sink and levees to fail. A major quake would threaten deltaarea levees, buildings, and bridges and much of the state's water supply.

\section{The Birth of U.S. Seismic Science}

Most experts agree that the 1906 San Francisco earthquake marked the beginning of modern earthquake science in the U.S. Three days after the earthquake, California Governor George Pardee commissioned an investigation led by Andrew Lawson, a professor of geology at the University of California at Berkeley (UCB).

Professor Lawson assembled a group of scientists, who, over the next two years, collected evidence of the quake's fault line. They mapped the entire 477-kilometer-long surface break of the San Andreas Fault and documented the fault's movement. They found fences, houses, and roads that were offset up to 6 meters.

The report listed intensity estimates for more than 600 sites, the largest compilation of intensities ever assembled for a single earthquake. It also noted the correlation of intensity with underlying geologic conditions. Areas situated in sediment-filled valleys sustained stronger shaking than areas on bedrock, with the strongest shaking occurring in areas of landfill.

The Lawson report, published in 1908 as The California Earthquake of April 18, 1906: Report of the State Earthquake Investigation Commission, contained 643 pages and 40 large maps. Seismologists and geophysicists continue to use it for its physical descriptions, maps, and timetables of the 1906 event. The Lawson report remains the most important study of a single earthquake, and many consider it the birth of modern seismology in the U.S. In addition, the Seismological Society of America was formed in 1906 following the quake.

In 1910, a second volume of the Lawson report was published, written by Harry Fielding Reid, professor of physics and geology at Johns Hopkins University. In this volume, Reid proposed that faults store stress until they can no longer hold it, at which point, they snap like a rubber band stretched too far and suddenly release the energy. The process then begins again. This theory is still the principal model of the earthquake cycle.

The 1906 earthquake was the first natural disaster to be well documented by photographs. UCB's Bancroft Library holds the single largest collection of 1906 photographs. These can be viewed, along with the Lawson report, at the 1906 San Francisco Earthquake and Fire Digital Collection Web site: http://bancroft.berkeley.edu/ collections/earthquakeandfire.

\section{Validating the Simulations}

The Livermore simulations have been validated by comparing the individual results within the study's modeling teams with ground motion data observed and recorded in the Lawson report after the 1906 quake (see the box below) and with seismograms recorded worldwide. USGS scientists, led by Jack Boatwright, created a detailed 1906 ShakeMap. Boatwright added sites to the map described in the Lawson report, such as displaced buildings, and conducted new investigations at many other sites. He converted earthquake intensity scales reported by the Lawson research team into measures of ground motion. The resulting map shows that the highest ground-shaking intensity actually occurred in and around Santa Rosa, located more than 30 kilometers from the San Andreas Fault. "I'm pleased that our simulations match Boatwright's findings," says Rodgers.

The 1906 earthquake was recorded by seismic stations worldwide. Seismograms trace the changing amplitude and frequency of the ground shaking beneath the instrument. From seismograms, scientists can determine the time, epicenter, depth, and type of faulting of an earthquake as well as estimate how much energy was released. Bay Area seismograms of the 1906 quake were highly complex because the shaking was so intense and the instruments did not have the range to record the motions on scale. Rodgers has compared the seismograms recorded in Europe with synthetic seismograms created by the advanced codes and found them to agree fairly well.

\section{Determining Slip Rate}

Livermore scientists are gaining a better understanding of the nature of earthquake faults by determining the rate at which tectonic plates slide past each other. Knowing the slippage rate of one tectonic plate against another helps to identify the accumulation of stress on the various segments of the fault and, hence, the likely frequency and magnitude of earthquakes. 
Lawrence Livermore is a member of the Bay Area Regional Deformation Network, which is a network of about 67 continuously operating Global Positioning System receivers at various sites in the Bay Area and northern California. The network was set up to measure the slip that is occurring across faults.

Livermore geophysicist Rick Ryerson is using the Laboratory's Center for Accelerator Mass Spectrometry for precisely dating crystalline rocks (a technique called morphochronology) to determine the long-term slip rates of earthquake faults in Tibet and California. Ryerson first views satellite images to locate geologic formations offset by tectonic plate movement. Earthquakes can leave rock surfaces exposed, and the interaction of these surfaces with cosmic rays produces cosmogenic nuclides. The levels of cosmogenic nuclides increase the longer a sample remains at Earth's surface. To date the rocks, Ryerson determines the ratio of concentrations of beryllium- 10 and aluminum-26 to stable isotopes in the crystalline rocks.

Ryerson has taken samples from the Tibetan plateau, where two tectonic plates have been slowly grinding past each other for millions of years creating, in the process, the Himalayas. (See $S \& T R$, June 2000, pp. 26-29.) He has also collected rocks from a portion of the southern San Andreas Fault just north of Palm Springs, where several strands of the fault converge. This method provides a new tool for evaluating faults in seismically active regions throughout the world.

\section{More Simulations on the Way}

As part of the Laboratory's Earthquake Hazards Group, Larsen, together with UCB collaborators, has used groundmotion simulations to investigate Bay Area bridges and freeway interchanges (with California Department of Transportation officials), dams (with the Federal Bureau of Reclamation), UC campus facilities,
Lawrence Livermore buildings, and area hospitals. Most recently, Larsen has been working with UCB scientists to simulate smaller Bay Area earthquakes. Of particular interest is the reliability of levees in the Sacramento-San Joaquin Delta under seismic force conditions. In this effort, Rodgers is hoping to examine the seismic resistance of the levees to earthquakes, especially to those on the Greenville Fault because of its proximity to the delta.

Rodgers is proposing additional simulations be done to gauge the effects

(a)

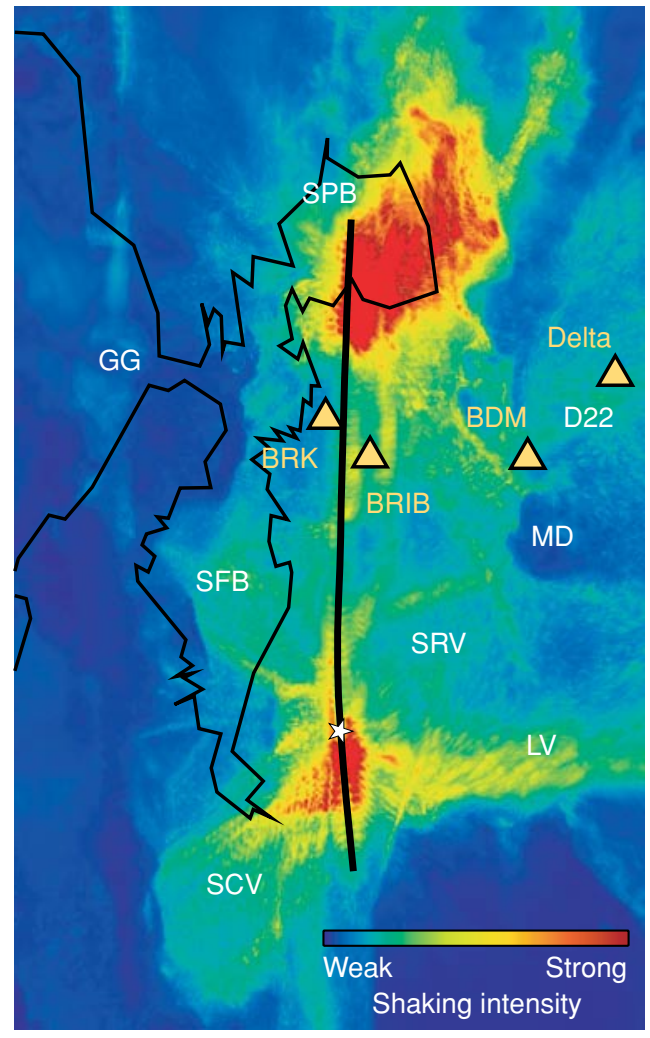

of strong quakes on local freeways, bridges, Bay Area Rapid Transit tunnels, and key facilities such as hospitals. "A major quake along the Hayward-Rodgers Creek, Greenville, or Calaveras faults could move the ground with velocity up to 1 meter per second," he says. "With that much ground motion, it is critical to assess what would happen to buildings and major structures."

Chad Noble, a Livermore structural engineer, has been using engineering codes to study how earthquakes affect dams, tunnels, and levees. Noble takes

(b)

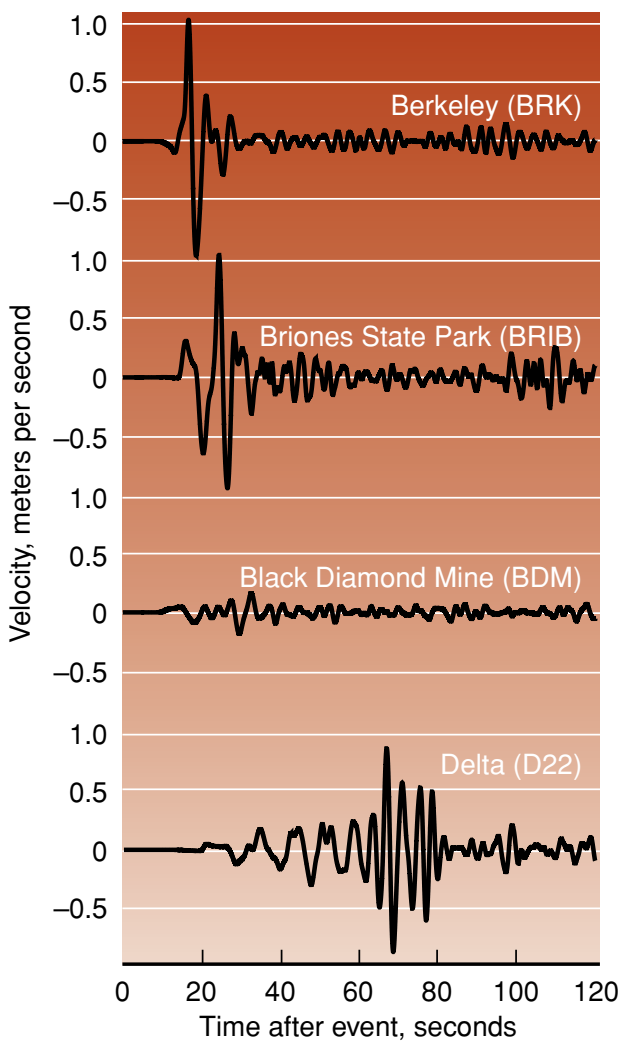

(a) A simulated magnitude 6.7 quake (epicenter is depicted by the star) on the Hayward-Rodgers Creek Fault (black line) causes strong shaking in the delta region, although it is located about 50 kilometers from the fault line. Abbreviations denote the following Bay Area regions: Golden Gate Bridge (GG), San Francisco Bay (SFB), Santa Clara Valley (SCV), Livermore Valley (LV), San Ramon Valley (SRV), Mount Diablo (MD), San Pablo Bay (SPB). Triangles denote locations of seismograph stations. (b) Synthetic seismograms show the probable activity these stations would generate from a magnitude 6.7 Hayward quake. The seismogram from the hypothetical D22 station along the Sacramento-San Joaquin Delta shows strong ground motion lasting much longer than at other locations in the Bay Area. 


\section{Applying Seismic Expertise to Nuclear Treaties and Waste Storage}

Livermore seismologists and geophysicists are major participants in the national program to provide the U.S. government with the technical capabilities needed for worldwide monitoring of several nuclear test ban and arms reduction treaties. Indeed, the strength of these treaties rests, in large part, on the technical capabilities available for monitoring compliance.

Livermore researchers focus on the Middle East, North Africa, and Russia. Their job is to help detect, locate, and identify events for the U.S. National Data Center at Patrick Air Force Base in Florida. Scientists calibrate seismic stations in these regions to ensure that seismograms of events are properly interpreted in light of regional geologic characteristics. An important issue is being able to discriminate nuclear explosions from naturally occurring phenomena, such as earthquakes, and other human-caused events, such as explosions used in mining and quarrying.

According to Dave Harris, Livermore's Ground-Based Nuclear Explosion Monitoring Program leader, an important effort is developing geophysical models that accurately predict seismic wave propagation in regions where scientists lack observations of prior seismic events. "We develop geophysical models for regions like North Africa that do not experience many earthquakes. It's helpful to have a model that synthetically generates probable seismograms."

With funding from the Laboratory Directed Research and Development Program, Rodgers and seismologist Michael Pasyanos are exploring the use of a stochastic engine to strengthen the predictive capability of models used in nuclear monitoring. Stochastic engines use advanced statistical methods and refined search methods to narrow the possible configurations of a model. (See $S \& T R$, July/August 2002, pp. 21-23.) In this case, the stochastic engine is used to predict the range of seismic signals geophysicists might expect to see from an event in a certain area. "The stochastic engine gives us a suite of models that fit a broad range of data," says Rodgers. "We can detect and identify weaker magnitude seismic events by making use of what we learn from the models."

Livermore scientists have also been applying their expertise to characterize the geology of Yucca Mountain, Nevada, and its surrounding region. The goal is to determine whether spent nuclear fuel and high-level radioactive waste could be safely isolated deep beneath the mountain's surface. As part of this site characterization, scientists have performed extensive studies to estimate the potential sizes and frequencies of future earthquakes and to determine the level of ground motion and fault displacement that might affect potential repository facilities, both on the surface and underground. Scientists have used the results of these studies to design repository facilities that will withstand earthquakes and to assess the long-term performance of the total repository system.

A variety of Livermore earthquake simulations can be viewed at http://www.llnl.gov/pao/news/news_releases/2006/quake_ simulations.html. seismic forces generated by Livermore seismological models and feeds them into structural finite-element models using two Livermore codes, DYNA3D and ALE3D. For the Federal Bureau of Reclamation, Noble and other Livermore engineers have analyzed the 3D response of some of the bureau's concrete dams to seismic forces. The simulations show the stresses on dams and their foundations and the movement of contained water in response to seismic waves.

"Earthquake ruptures are not uniform but slip in ways that reveal differences in friction, rock strength, and stress," says Rodgers. "A magnitude 6.5 earthquake could have widely varying ground motion because of variations in the rupture that cannot be predicted. We hope to look at suites of simulations on Bay Area faults to account for rupture variability. In this way, we could reduce the uncertainty in ground-motion predictions."

The results of the simulations will offer disaster planners the ability to more accurately predict where the ground will shake most severely during another major Bay Area earthquake. Scientists will not be able to prevent the Next Big One, but they can provide officials and the public more information to better plan for it.

-Arnie Heller
Key Words: ALE3D, CODE3, DYNA3D, E3D, earthquake, Hayward-Rodgers Creek Fault, Lawson report, Loma Prieta earthquake, morphochronology, Sacramento-San Joaquin Delta levees, San Andreas Fault, seismology, ShakeMap, spectral element method (SEM), U.S. Geological Survey (USGS), Wave Propagation Program (WPP), 1906 San Francisco earthquake.

For further information contact Arthur J. Rodgers, Jr. (925) 423-5018 (rodgers7@IInl.gov). 


\section{Decoding the Origin}

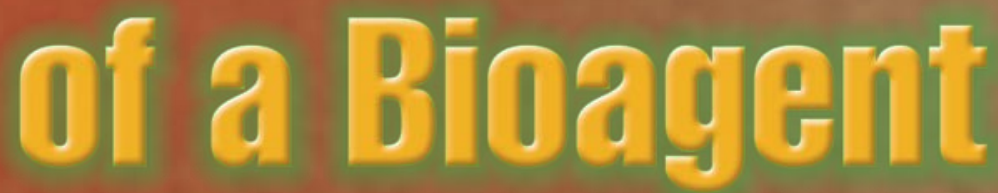

\section{Researchers}

\section{are discovering}

\section{relationships}

\section{between a pathogen's}

\section{microstructure and its}

\section{provenance.}

MONG the possible threats to life, 7 few are as frightening as a weapon we can't see directed at us from an enemy we can't identify. Nanometer- to micrometersize microorganisms can make powerful covert weapons, and the capability to detect and trace their origin has become a national security priority. Microbial forensics is a new area of research, the goal of which is to provide scientific tools to uncover how, when, where, and by whom a biological agent was made.

Prior to 2001, nascent efforts to build a forensic capability for analyzing microorganisms were already under way within the National Nuclear Security Administration's Chemical and Biological National Security Program. In 2001, the attacks in the U.S. in which Bacillus anthracis spores were included in mailed letters revealed the need for a more extensive national microbial forensics research and development program. Experts used genetic typing to determine

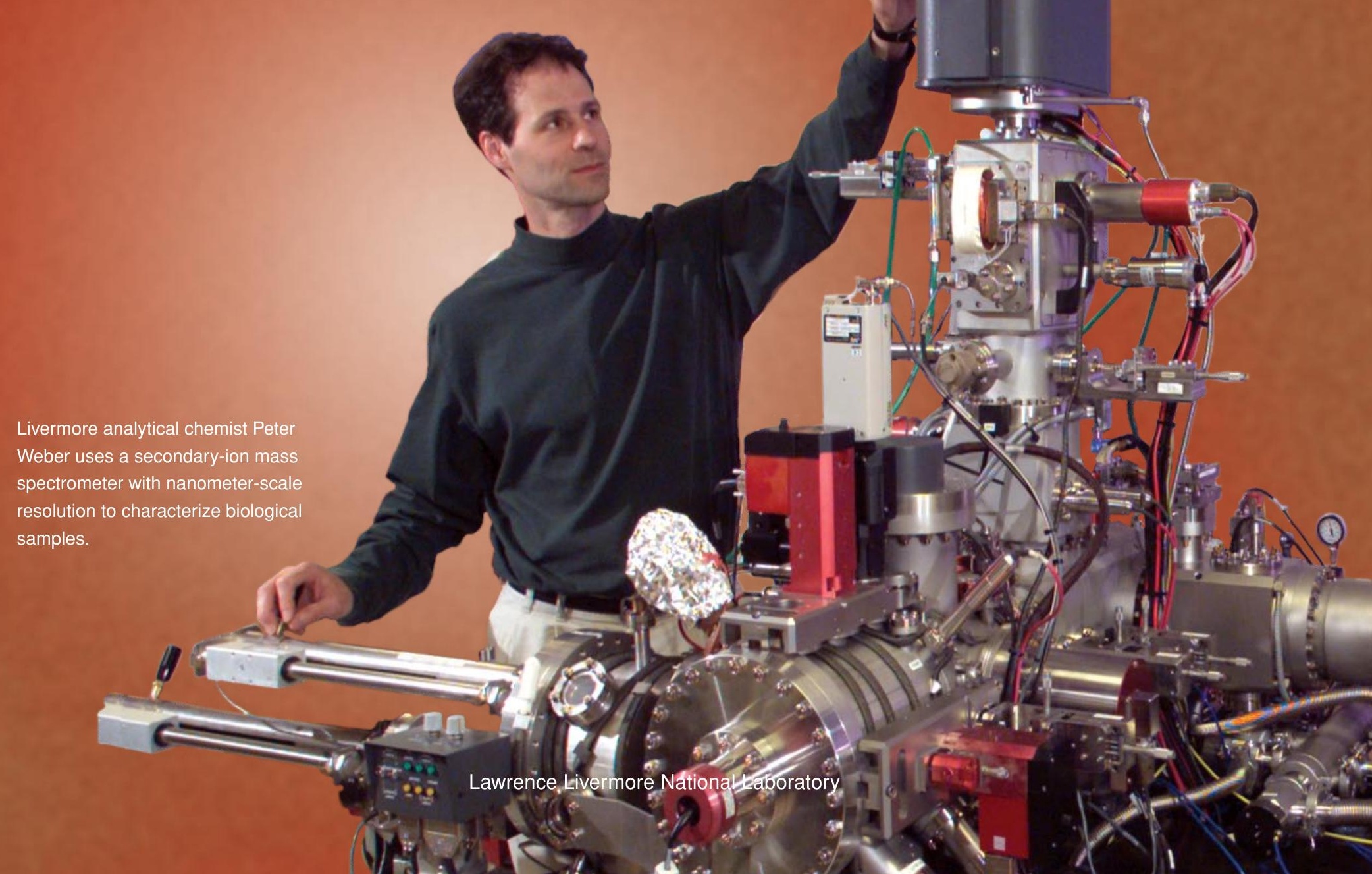


that the letters contained the $B$. anthracis Ames strain, but they had few other methods available for tracing the spores further to their source.

\section{Bioterrorist Wake-up Call}

The 2001 letter attacks galvanized the national security community to assess the status of the nation's microbial forensic capability and develop protocols to better handle such attacks. One of the first actions after the Department of Homeland Security (DHS) was formed was to establish the National Bioforensics Analysis Center (NBFAC). Working with the NBFAC, the Federal Bureau of Investigation (FBI) formed a Scientific Working Group for Forensic Analysis of Microbial Evidence (SWGFAME), bringing together dozens of experts around the country. Lawrence Livermore has an important role in the working group, providing new technologies and scientific expertise.

Chemical physicist Steve Velsko, one of several Livermore scientists serving on the SWGFAME, leads a team that is applying the Laboratory's expertise in biology, chemistry, and materials science to solve microbial forensics problems. The researchers use techniques such as atomic force microscopy and secondary-ion mass spectrometry to determine whether structural features of microorganisms can be correlated with the methods used for growing and preparing the microbes. They are also developing new genetic typing techniques that could be used to quickly determine if a bacterial strain used in a bioterrorist incident is related to one found in a suspect laboratory.

"The difficulty," says Velsko, "is that much of the fundamental science needed to interpret both DNA and nonDNA evidence remains to be elucidated. Biological organisms such as $B$. anthracis can be found in many locations, which makes unambiguous tracing of pathogens to a single source very difficult. Sometimes it is even difficult to recognize that an attack has occurred." For example, about 300,000 hospitalizations and 5,000 deaths are attributable each year to food-borne illnesses in the U.S., and it is not always obvious whether these are a result of natural or intentional causes.

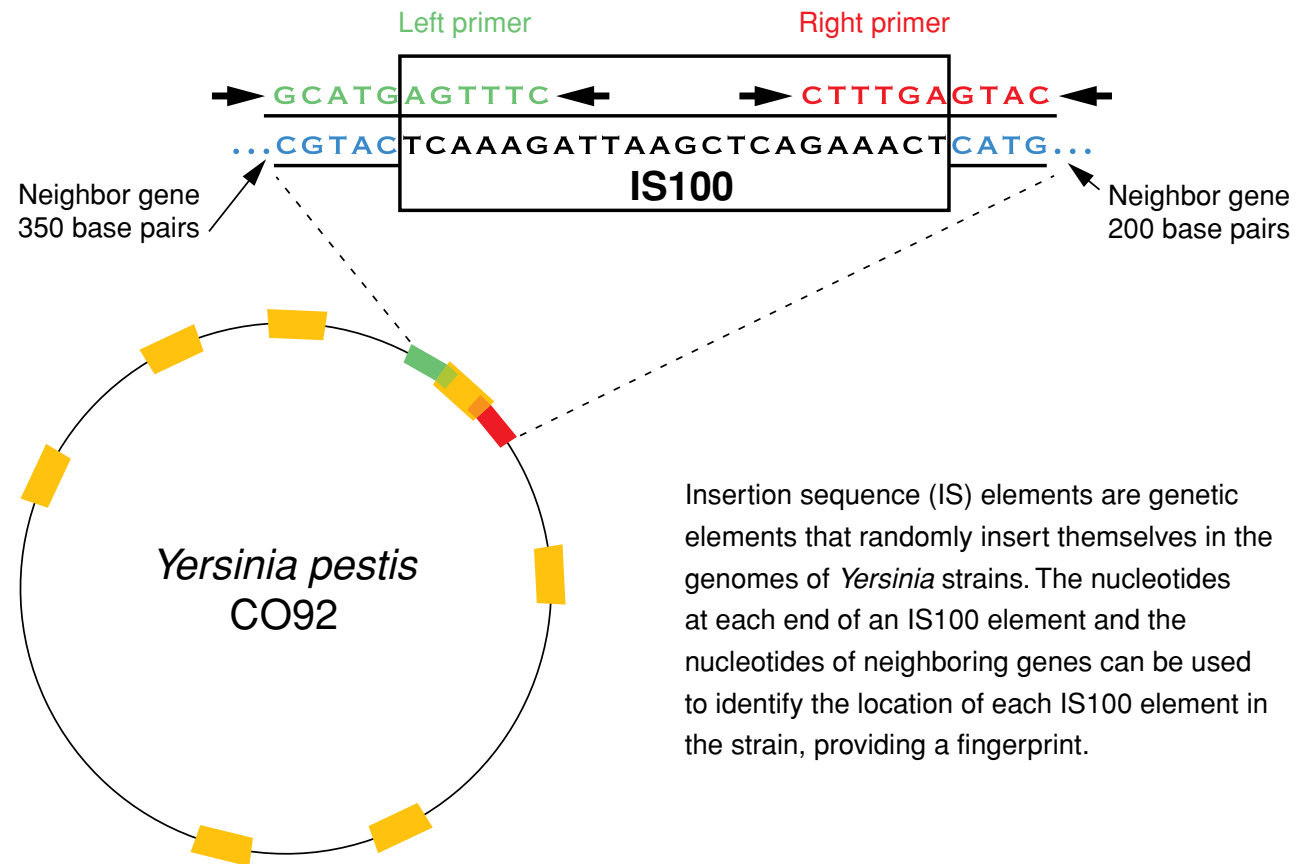

The Centers for Disease Control and Prevention maintains a database of select biological agent holdings at U.S. laboratories. Biological threat agents fall into three categories: viruses, bacteria, and toxins. The agents of most concern include those that may have been involved in foreign state-sponsored bioweapon programs: B. anthracis, Yersinia pestis (plague), Franciscella tularensis (tularemia), Burkholderia species (glanders and melioidosis), Brucella species (brucellosis), and Variola (smallpox).

"In 2001, the Ames anthrax strain was believed to be held by seven or more laboratories," says Velsko. "If the spores used in the attacks originated from one of those labs, just a short amount of time may have passed between the time the spores left the lab and when material grown from them was released. If so, the DNA of the strain in the letters may not be very different from the strains in these labs." When pathogens are transferred from nature to a laboratory, or between laboratories with different growing conditions, mutations (polymorphisms) can occur that shift the majority genotype away from that of the original strain. Improved genetic typing methods are needed to quickly identify these changes among closely related samples of bacteria.

\section{High Cost of Lengthy Genomes}

Typically, bacterial genomes contain 3 to 5 million DNA base pairs. Viruses are smaller, containing fewer than 200,000 nucleotides of RNA or DNA. Comparing the entire genomic sequence of two or more organisms is the most accurate identification method available. However, the cost of this method makes it impractical in a forensic investigation involving a potentially large number of pathogen samples, except in the case of small RNA viruses. For example, the estimated cost is about $\$ 140,000$ to determine with high confidence the sequence of one $B$. anthracis genome containing approximately 5.5 million base pairs. Sequencing 7 to 10 samples could 
cost well over a million dollars. Therefore, researchers generally use sequencing to identify just the highly variable regions of bacterial pathogenic genomes.

Recently, researchers have developed less costly and faster approaches to genetically differentiate related strains of microorganisms. For example, advancements in partial genomic sequencing have led to a genetic typing system for $B$. anthracis. These systems look for polymorphisms in segments of the genome known to be particularly susceptible to mutation. However, one drawback to virtually every genetic typing system is that only fragments of a genome are examined, and these fragments may or may not capture all the significant changes in the genome. Thus, a challenge for researchers is to choose the most effective genetic typing system for detecting a particular polymorphism.

One important tool incorporated into a number of genetic technologies is the polymerase chain reaction (PCR). PCR is a technique for replicating DNA fragments in a test tube. The technique is used to copy a small number of DNA molecules up to millions of times, thereby amplifying a specific portion of the genetic material to an amount that can be detected. (See $S \& T R$, May 2000, pp. 4-12.) Researchers determine which small DNA fragment to amplify by selecting primers-DNA strands usually between 18 and 25 base pairs long - that are complementary to the beginning and end of the DNA fragment of interest. They subject the DNA fragment to a process that separates the two DNA strands. The primers then adhere to complementary sequences on the single DNA strands, where a DNA polymerase catalyzes DNA replication and extends the targeted genetic sequence.

\section{Locating Mutation Positions}

Through funding from DHS, Livermore microbiologist Emilio Garcia leads a team that is developing a novel PCRbased genetic typing system. The new system uses a class of genetic elements called insertion sequence (IS) elements to distinguish among different strains of the same bacterial species. IS elements are repetitive units of DNA that have randomly inserted themselves at multiple locations throughout a bacterial genome. Different families of IS elements can vary in size and composition. IS elements have been observed in a variety of pathogenic bacteria, including $F$. tularensis and Y. pestis, and may play a role in providing bacteria the capability to quickly adapt to changing environments.

Researchers have used several molecular methods to confirm the presence of three IS elements unique to YersiniaIS100, IS285, and IS1541. These insertion elements have been sequenced, but no efficient process has been available to locate their positions within a strain's genome. Garcia's new typing method allows researchers for the first time to effectively group and identify strains based on the positions of known IS elements in the $Y$. pestis genome.
Last year, the team compared the location of IS100 elements in a large collection of strains from the three $Y$. pestis groups, called biovars. Each of the biovars - Orientalis, Medievalis, and Antiqua - evolved in different geographic regions of the world. Garcia's team used the nucleotides at the ends of an IS100 element, along with primers the team designed, to hook the ends on both sides to neighboring genes. The team then identified the location within the genome of each IS100 element in the strains. The Y. pestis strain CO92, whose genome has been completely sequenced, was used as the reference genome.

The team used the IS100 sequences and the DNA sequences surrounding those in the $\mathrm{CO} 92$ genome to design the primers for the experiments. They included 44 different IS100 insertions in 113 Yersinia DNA samples. Results showed that it was possible to distinguish among $Y$. pestis strains within each biovar and from distinct geographic regions. The team has also applied the typing system

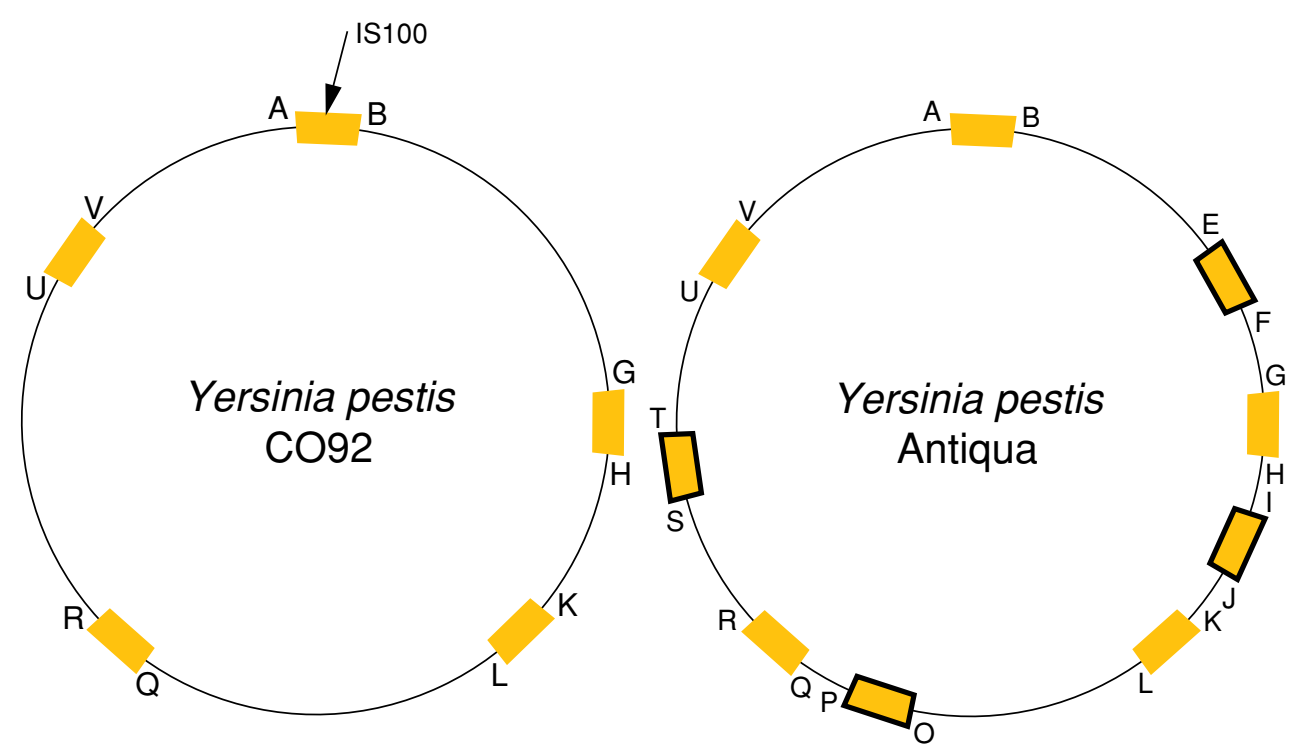

A schematic shows how the locations for IS100 elements in the Yersinia pestis CO92 strain, whose genome has been completely sequenced, can be used as a reference to determine if an unknown Yersinia strain (here Yersinia pestis Antiqua) is related. The letters refer to specific locations on the genomes. The black-framed elements denote locations unique to Antigua. 
to locate IS285 in Yersinia strains. "IS element fingerprinting can provide the right amount of discriminatory power because IS elements evolve more slowly and are more stable than random variations," says Garcia.

Paul Jackson, forensics group leader in the Laboratory's Biosciences Directorate, also serves on the SWGFAME. Jackson is applying genetic typing methods to biological toxins. "The active ingredients

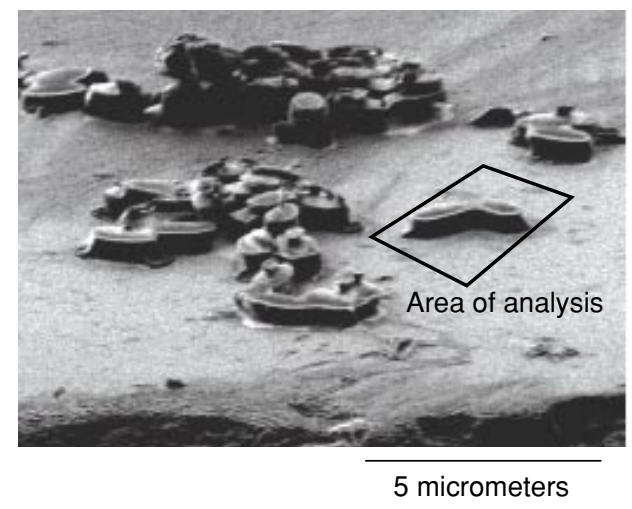

Using a focused ion beam instrument, researchers can select and extract areas of a spore for further analysis with a nanometer-scale secondary-ion mass spectrometer (NanoSIMS). in biological toxins are proteins, not DNA," says Jackson, "but they are derived from cellular organisms and always contain traces of their original biological source DNA. This residual DNA can be used as a fingerprint for the original source of the toxin." Jackson is studying the DNA of the Ricinus communis plant, whose seeds are the source for ricin, one of the most deadly toxins. The FBI is currently investigating a number of cases involving ricin, which is believed to be the most common bioterrorism agent used worldwide. "Investigators need methods for determining whether two ricin samples were made from the same batch of seeds, and whether the seeds came from a particular geographic region," says Jackson.

To characterize the DNA of the $R$. communis plant, Jackson uses a method called amplified-fragment-length polymorphism typing, in which the DNA is first cut into characteristic short fragments using one or more restriction enzymes. Certain fragments are then amplified using a PCR method. The lengths of the amplified fragments are determined using a DNA sequencer, similar to the way in which DNA fragment sizes are determined in genomic sequencing. Jackson's team is analyzing DNA in more than 200 types of $R$. communis plants from many geographic locations to determine the genetic diversity among the world's sources. "This information will help classify the possible sources of natural ricin and select the appropriate genetic types for more detailed analyses such as sequencing," says Jackson.

\section{Structure and Formulation Connect}

In addition to genetically based approaches to microbial forensics, the Livermore team is exploring technologies that could potentially provide other types of information on the origin and source of biological agents. "Remnants of growth media, stabilizers, or additives as well as incidental biocontaminants, such as environmental pollens that adhere to the spores, may provide clues about processes used to enhance the lethality and delivery of a biological agent," explains Velsko. One goal of the national program is to develop a reference database of chemical and physical signatures that growth and processing methods leave on a biological agent.
NanoSIMS images of the same type of spore grown in two nutrients, $G$ agar (top row) and NB agar (bottom row), show different ion concentrations of the elements phosphorus, fluorine, and chlorine, which may provide a signature. Brighter colors indicate areas of higher ion concentration.
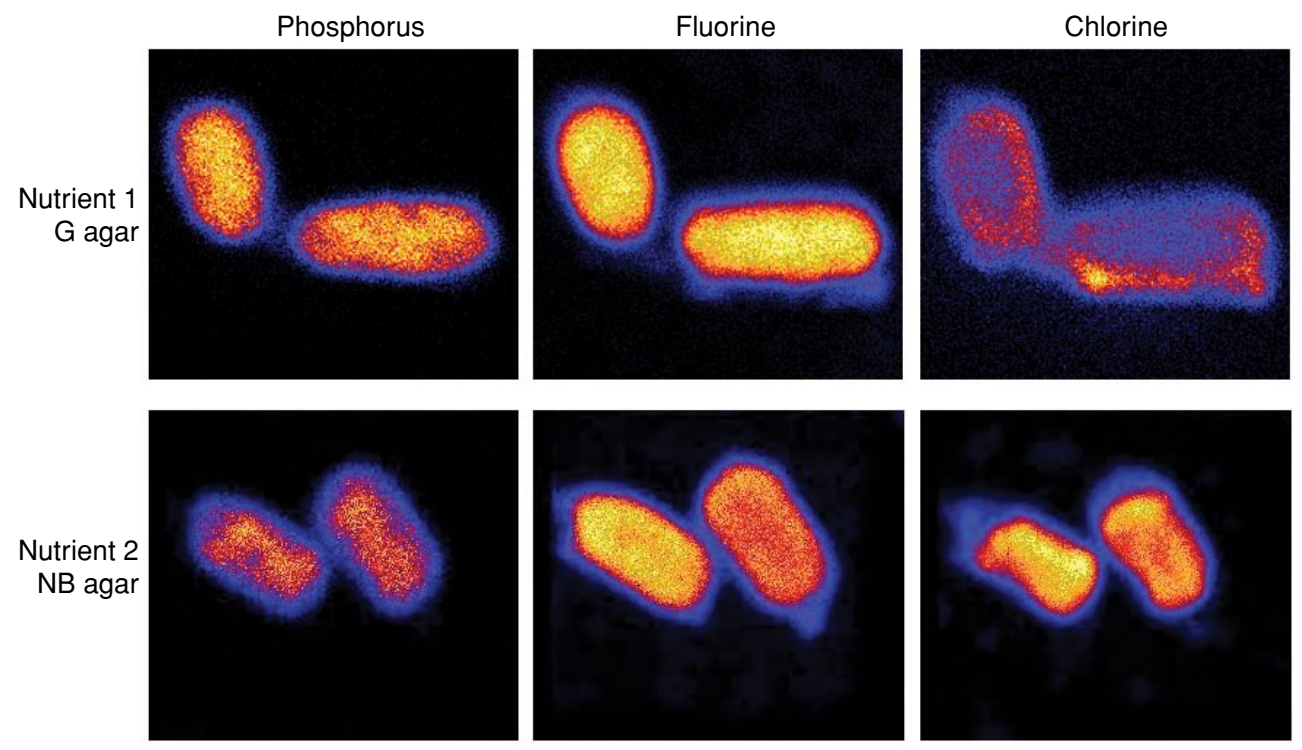

500 nanometers 
With funding from DHS, FBI, and the Laboratory Directed Research and Development (LDRD) Program, analytical chemist Peter Weber uses Livermore's nanometer-scale secondary-ion mass spectrometer (NanoSIMS) to conduct studies on biological agents. In this technique, a sample is bombarded with an ion beam; atoms on the surface of the sample are ejected and then analyzed in the mass spectrometer.

Livermore's NanoSIMS provides a spatial resolution of 50 nanometers, 20 times better than that of conventional SIMS. Its sensitivity is 50 times better. Weber's team is hoping to gain insight into possible links between the chemical composition of microorganisms and how, when, and where they were produced. These studies might also help resolve some of the uncertainty that exists with regard to conclusions drawn from research using surrogates of lethal pathogens. Weber says, "Biological weapon agents can be produced using a variety of methods. In addition to the microorganism, there may be a matrix of agents intended to enhance delivery. Plus samples collected from different environments may contain contaminants from external material."

The team has also used a focused-ionbeam instrument to extract slices from targeted areas of a sample before analyzing the composition with NanoSIMS. Bacterial spores are composed of approximately 50 percent carbon, 15 percent nitrogen, 3 percent calcium, 1 percent phosphorus, and trace amounts of about 20 other elements. Chemically related elements can substitute for one another. For example, strontium and barium are related to calcium and can substitute for it. Substitutions may be signatures of certain growth or processing methods.

The high resolution achievable with NanoSIMS allows Weber's team to analyze not only individual spores but also the elemental distribution inside the spores.
These analyses can reveal microstructural production signatures. Previously, only major elemental distributions could be studied. The NanoSIMS team, however, can detect the distribution of less abundant elements, such as chlorine and fluorine, to study how spore production methods may change their distribution.

Weber's team is studying $B$. thuringiensis and the Sterne vaccine strain of $B$. anthracis to develop a matrix of elemental and isotopic signatures for spores that have undergone various growth and processing methods. Terrance Leighton from Children's Hospital Oakland Research Institute collaborates with the Livermore team and provides them with samples. In addition,

(a)

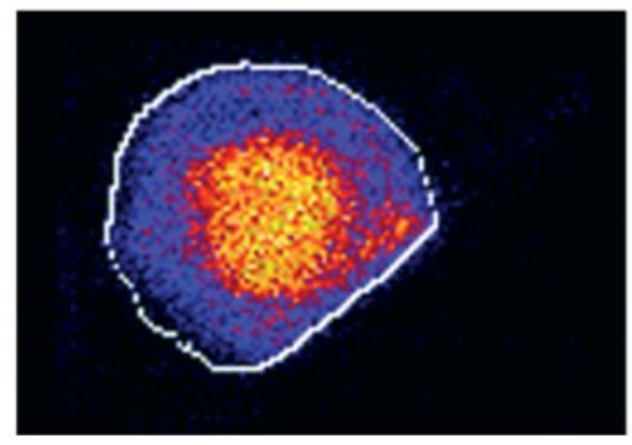

(c)

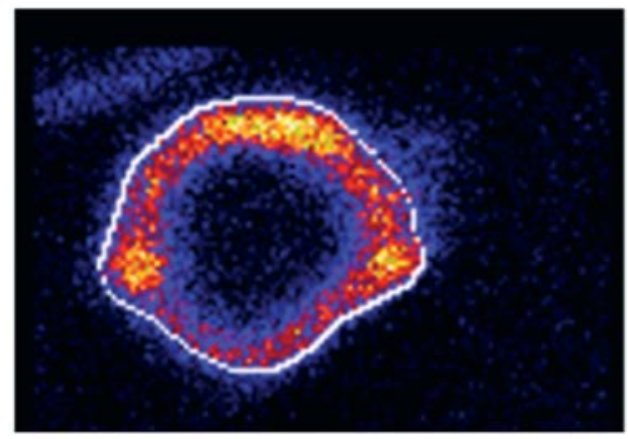

500 nanometers

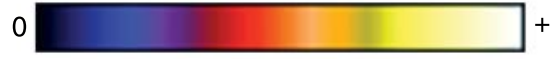

NanoSIMS images of a Bacillus thuringiensis spore that was sectioned using a focused ion beam show ion concentrations of abundant elements such as (a) phosphorus and (b) sulfur as well as concentrations of trace elements such as (c) chlorine and (d) fluorine. Brighter colors indicate areas of higher ion concentration. (b)

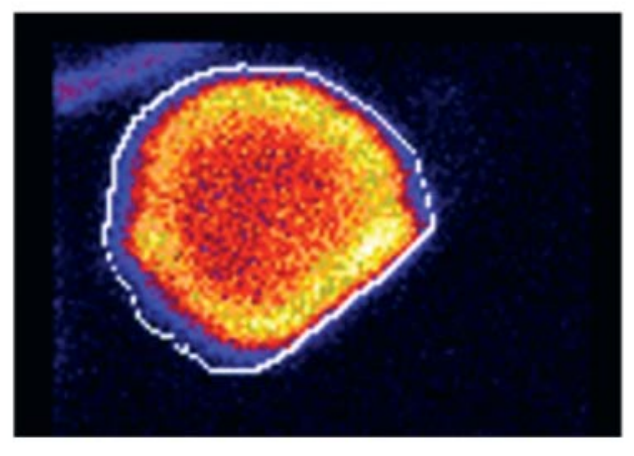

(d)

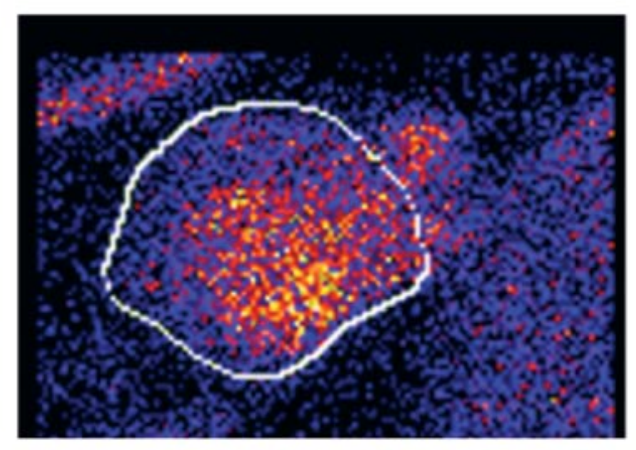

NanoSIMS is contributing to a study to determine whether diffusion rates of different elements in and out of spores could establish the date an agent was manufactured.

\section{Unique Surface Architectures}

The Livermore team is also using atomic force microscopy (AFM) for its forensic studies. One advantage of AFM is that it can be used to image biological samples in fluids under native conditions as well as air-dried samples. A second advantage is that it can achieve resolutions of about 1 nanometer, allowing researchers to analyze high-resolution pathogen structures.

The AFM instrument has an ultrasharp tip that scans across a sample's surface.

\section{(1)}


(a)

Atomic force microscopy images of air-dried (a) Bacillus anthracis and (b) Clostridium novyi-NT spores show different morphological features even at relatively low resolution. (b)

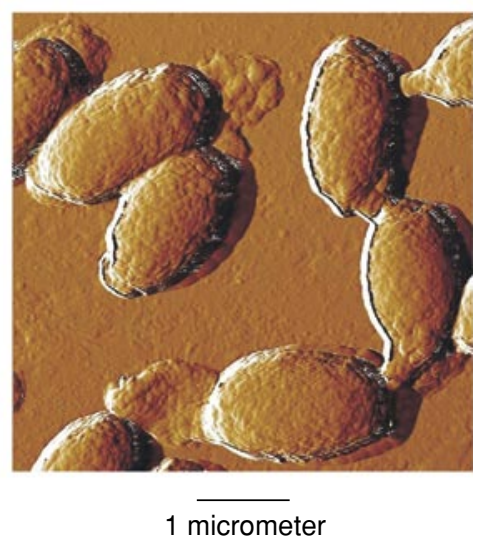

A high-resolution image of the sample's topography is constructed as the molecules on the surface of the sample interact with those on the microscope's tip. Livermore researchers have used AFM to study crystal growth in biomineralization and corrosion resistance in metals, to measure mechanical properties of soft materials, and to investigate the surface architecture and assembly of viruses and bacterial spores. (See $S \& T R$, December 2001, pp. 12-19; May 2002, pp. 11-15; May 2004, pp. 4-11.)

Although entire genomes have been sequenced for several Bacillus species, their spore-coat structures are not very well understood. Through funding from the LDRD Program and the FBI, Livermore chemist Alex Malkin and postdoctoral researcher Marco Plomp are investigating the structure-function relationships of bacterial spores.

The team provided the first highresolution AFM images of the native sporecoat structures of four Bacillus species and a Clostridium novyi-NT isolate. "We found that strikingly different spore-coat structures are a consequence of species-specific nucleation and crystallization mechanisms," says Malkin. "These mechanisms, which regulate the assembly of the outer spore coat, are similar to those for growth of inorganic and macromolecular single crystals. We can thus apply the concepts that have been developed to study the growth of these crystals to examine the assembly of spore coats."

The team found that the outer spore coats resembled honeycomb or rod-shaped structures, depending on the nutrient used to grow the cells. "The results established for the first time that outer coat structural patterns can be a formulation signature," says Malkin.

Leighton has produced and characterized a library of spores from the $B$. anthracis Sterne vaccine strain using a range of media formulations. The Livermore team applies AFM to examine the high-resolution structure of air-dried and hydrated B. anthracis spore samples. For comparison, they use killed (irradiated or chlorine dioxide-treated) Ames strain spores. "We now have the capability to conduct AFM characterization of pathogens authorized at the necessary biosecurity level to study vaccine strains of anthrax and smallpox," says Malkin. (a)

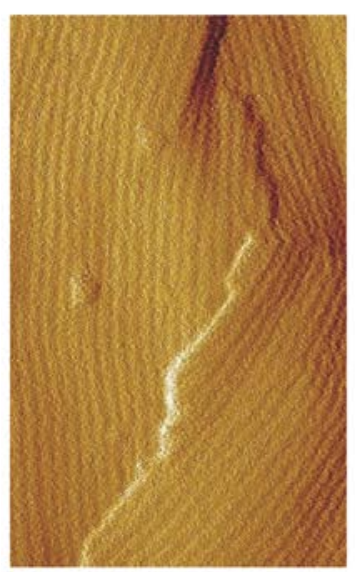

50 nanometers (b)

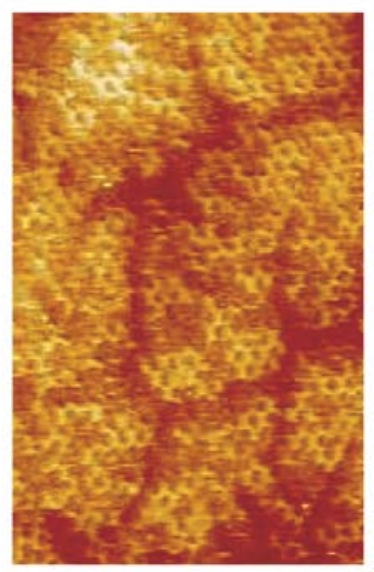

50 nanometers (c)

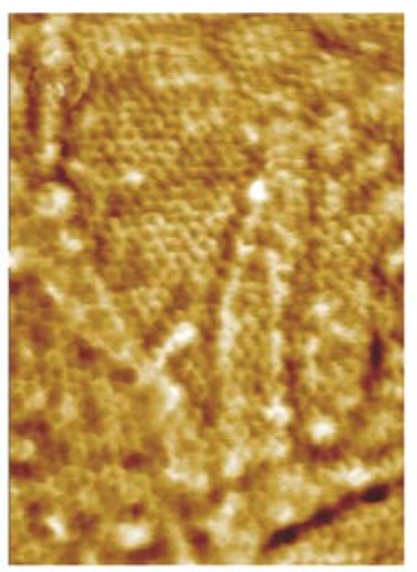

50 nanometers (d)

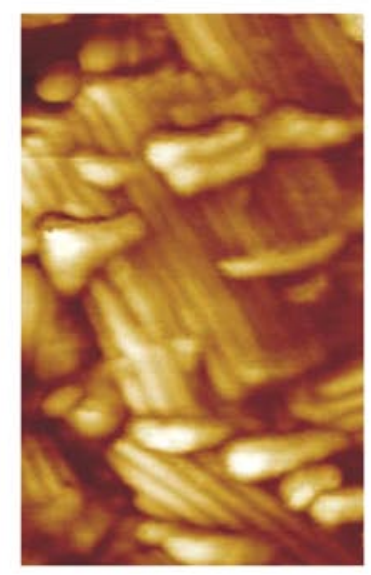

50 nanometers (e)

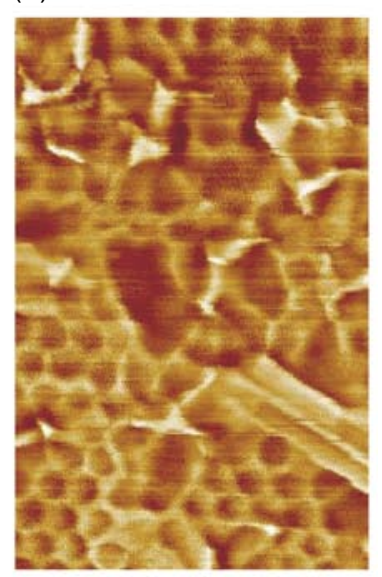

50 nanometers

Atomic force microscopy provides the first high-resolution images of native spore-coat structure. The outer spore coat of (a) Bacillus atrophaeus consists of crystalline layers of rod-shaped structures while the outer coats of (b) B. thuringiensis and (c) Clostridium novyi consist of honeycomb structures.

(d) B. cereus is covered with small domains of rodlets and has (e) a honeycomb structure beneath. 


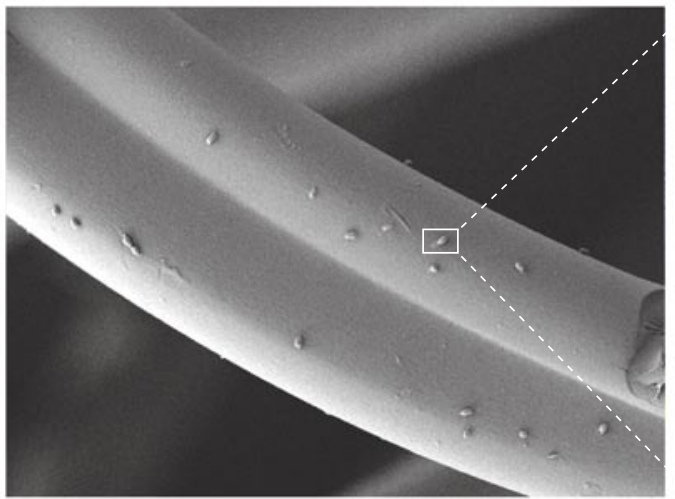

10 micrometers

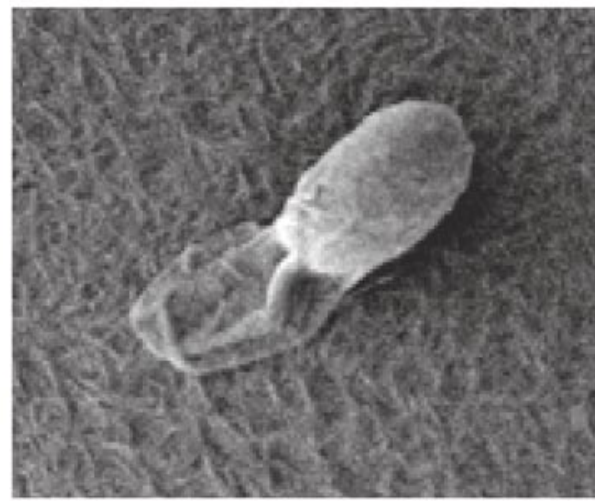

1 micrometer
The team is also developing an experimental approach called AFM-based immunolabeling. A spore's coat is composed of about 30 proteins and, under different conditions, the coat composition changes. The team uses antibodies labeled with gold particles to characterize the influence of growth and processing conditions on the proteomic structure of $B$. anthracis spore surfaces. They have also developed a technique to dissect a spore coat layer by layer. The technique has allowed researchers for the first time to define the complete architecture of the spore coat.

\section{Collecting the Evidence}

The FBI and other investigative agencies also require methods for collecting and extracting biological threat agents and their DNA from crime scenes and other locations.

Investigators often search for microbial evidence among fibrous materials, such as cloth, carpet, building ventilation filters, and paper, because these materials harbor agents well and it is difficult for the criminal - or a routine cleaning person - to remove these agents. However, it is also difficult for investigators to efficiently collect and extract spores and DNA from fibrous materials, and samples may include only trace amounts of an agent.

Livermore chemical engineer David Camp and his team are developing improved methods to separate colloidal
B. anthracis spores and DNA from fibrous materials and their contaminants. In an effort led by chemical engineer Elizabeth Wheeler, a technique was developed and demonstrated that is 10 times more sensitive than commercial DNA cleanup kits at recovering trace amounts of B. anthracis DNA from challenging dirty suspensions. The NBFAC hopes to incorporate this technique into its automated sample processing system.

\section{Capability on Its Way}

Since the SWGFAME was formed, the Laboratory has developed several new complementary technologies to increase our nation's microbial forensics capability. "Forensics data are most valuable when different techniques provide the same results," notes Malkin. NanoSIMS, AFM, gene typing, and other technologies are being combined to construct an attribution profile for microorganisms turned into bioweapons. "Strain identification must be quick enough to allow for an adequate medical and public health response, yet it must also endure the rigorous standards for evidentiary material that may be presented in a courtroom," says Velsko. It's a tall order. Still, Velsko is optimistic that the research avenues being investigated will soon provide the necessary capability. -Gabriele Rennie
A flexible hydrophobic outer membrane, or exosporium (spore overcoat), of Bacillus anthracis strengthens its adhesion to fibers.

Key Words: atomic force microscopy (AFM), Bacillus anthracis, biological agent, Clostridium novyi-NT, genetic typing, insertion sequence (IS) elements, microbial forensics, nanometer-scale secondaryion mass spectrometry (NanoSIMS), National Bioforensics Analysis Center (NBFAC), polymerase chain reaction (PCR), polymorphism, Scientific Working Group for Forensic Analysis of Microbial Evidence (SWGFAME), Yersinia pestis.

For further information contact Steve Velsko (925) 423-0191 (velsko2@IInl.gov). 


\section{A New Look at How Aging Bones Fracture}

A curse of aging bones is the increased possibility of fractures, even with small amounts of stress. A bump or fall that would only bruise a younger person can mean a broken hip or a fractured vertebra for an older person who has developed osteoporosis, a disease attributed to the loss of bone. In fact, spinal fractures are the most common injury associated with the disease.

In most medical circles, this decrease in bone density is believed to be the direct cause of osteoporotic fracture. However, a team of scientists from Lawrence Livermore, the University of California (UC) at Berkeley, and UC Davis has been exploring another possible cause for increased fractures in aging bones. "Our research suggests that a change in the bone's physical structure causes it to fail," says Livermore's John Kinney, the physicist who heads up the project. "In a young vertebra, fracture is governed by the strength of the hard tissue that makes up the bone. We have discovered that, in osteoporotic bone, fracture is controlled not by the strength of the bone tissue but by the manner in which it fails." Kinney obtained funding from Livermore's Laboratory Directed Research and Development Program to examine the biomechanics of spinal fracture.

\section{Building Blocks of the Spine}

In an effort to explore the mechanisms by which fracture occurs in aging bone, Kinney's team studied the bone structure of individual vertebra in the spine. The human vertebra is composed of an open-celled lattice material called trabecular bone. This bone's cellular foam structure makes it look like sponge. Trabecular bone is also found nearest the joints in large bones, such as the femur (the long bone that joins knee to hip), the tibia (the larger of two bones connecting ankle to knee), the humerus (the long bone connecting shoulder to elbow), and the iliac crest (the upper and widest part of the hip bone). The spongelike trabeculae absorb loads from the joints, similar to how Styrofoam (another open-celled lattice material) used in packaging absorbs impacts.

All living bone "turns over" regularly. That is, old bone is absorbed back into the body (resorption process) and is replaced by new bone (formation process). The average turnover rate for bone is about six years, with that rate being faster for sites close

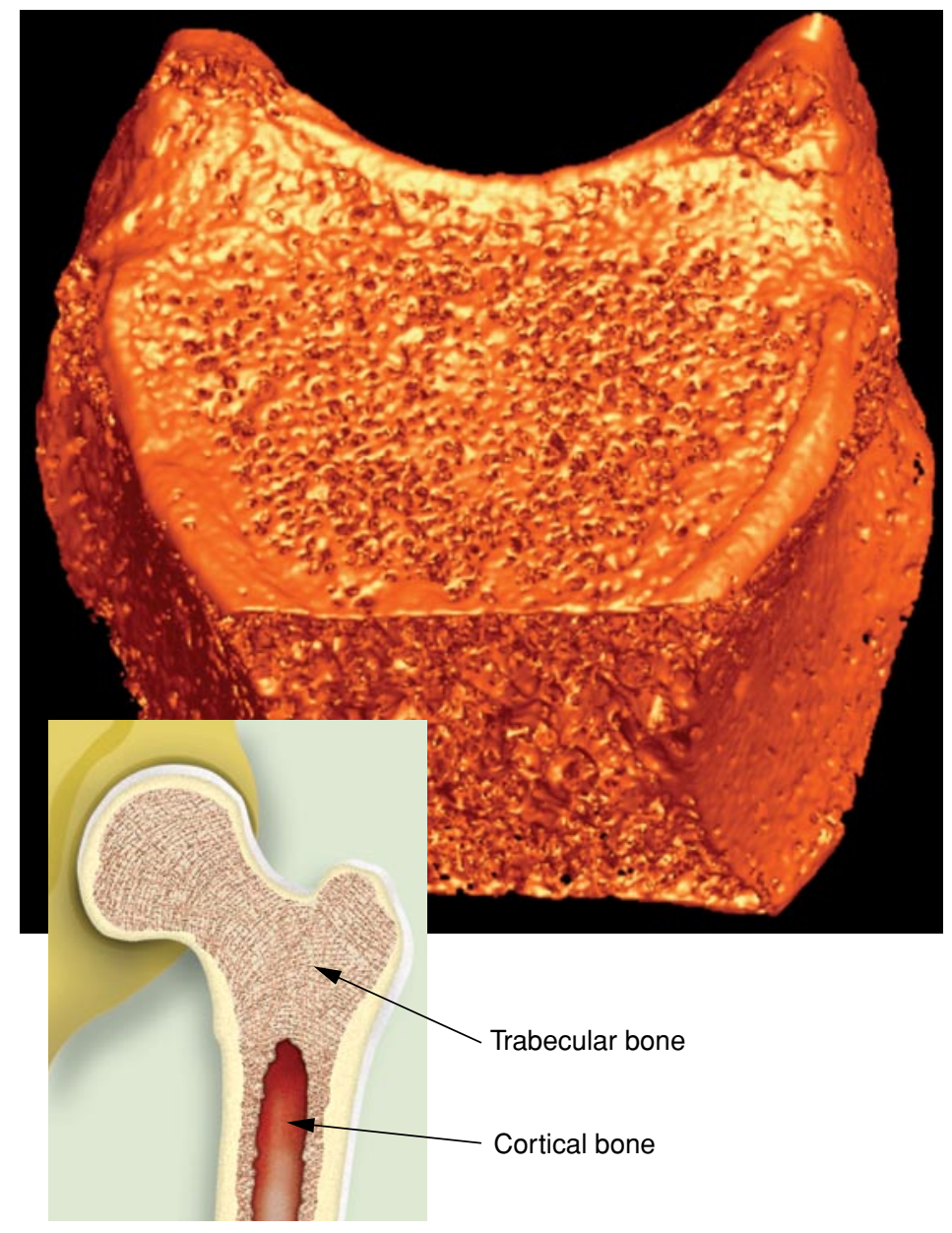

In adult humans, cortical and trabecular are the two main forms of bone. The spongelike trabecular bone is found nearest the joints in the femur (inset), tibia, humerus, and iliac crest bones as well as in vertebrae. The human vertebra shown above was imaged using a charge-coupleddevice camera operating on a beamline at Lawrence Berkeley National Laboratory's Advanced Light Source.

to a blood supply such as at the hip and in vertebrae. However, this turnover process changes as a person ages, particularly in menopausal women.

"At menopause, women experience an acceleration in bone turnover," explains Kinney. "Because an imbalance exists between resorption and formation, with more bone resorbed than formed, an accelerated loss of bone mass occurs during this stage in life." Medical treatments for osteoporosis focus on retarding bone loss by inhibiting this turnover process. "The thought is," says Kinney, "that by stopping the reabsorption of old bone while new bone continues to fill in, albeit slowly, the bone mass will stabilize, resulting in fewer fractures." 


\section{Buckling Backbone Up Close}

Kinney and his team departed from the usual assumption that the increase of fractures in aging bone is due entirely to lower bone density. Instead, they focused on the possibility that aging bone fractures result from a loss of stability, or buckling, in the structure of the bone lattice. Kinney, along with metallurgist James Stolken from the New Technologies Engineering Division and Nancy Lane from UC Davis, tested this hypothesis using advanced imaging and computational methods.

Vertebrae were obtained from the skeletal archives of the Smithsonian Institution and imaged in three dimensions (3D) using a beamline at Lawrence Berkeley National Laboratory's Advanced Light Source. "We could see from the 3D images that the number and thicknesses of the trabeculae forming the bone were different in young and old bone," says Kinney. In young bone, the trabeculae form a web of short, stubby struts. However, in older bone, these trabeculae are long and slender, and fewer of them exist.

Kinney says, "We wondered if buckling - a mechanical failure of the bone structure itself - could be to blame for some of the fractures that clinicians see. Although a few other researchers had hypothesized that this might be the case, the possibility that trabeculae could buckle had largely been ignored." To explore how vertebrae fail, Kinney and his colleagues combined the detailed structural information gained from the images with finite-element simulations using a parallel version of NIKE3D, which had been developed by Robert Ferencz at Livermore.

The simulations, which were performed on Livermore's MCR Linux-cluster supercomputer, revealed that a new failure mode occurs in older bone consisting of longer, more slender trabeculae. In younger trabecular bone, strength-initiated failure dominates, in which the stress overcomes the strength of the bone tissue. In older bone, stability-initiated failure dominates because of the instability of the individual trabeculae. That is, older bone is prone to inelastic buckling at stresses far less than expected for strength-based failure.

Buckling is characterized by a sudden failure of a structural member subjected to compressive stress. At failure, these compressive stresses are actually far lower than the compressive stresses that the material itself is able to withstand. The likelihood of a columnlike structure such as bone buckling depends in general on the ratio of the structure's length to its cross section.

A common example of buckling may be observed when crushing an empty aluminum can. Like a vertebra, the can is loaded axially and when subjected to sufficient loads, it will fail via a buckling instability. Stolken provides a simple example of the sensitivity of buckling to geometric imperfection using two empty aluminum beverage cans. Place the first can, which is undented, on the floor and crush it by stepping on the top, being careful to step as evenly as possible. The can should support a significant fraction of one's body weight before failing. Now repeat the experiment using the second can, which has a small dent in the side wall. The dramatic difference in failure load is due to the initial imperfection (dent).

"Of greater significance, we also found evidence that the osteoporotic vertebrae are hypersensitive to small imperfections," said Kinney. "Small pits on the surfaces of the trabeculae, caused by the cellular process of bone resorption, increase in number as the bone turnover rate accelerates. The pits are enough, in and of (a)

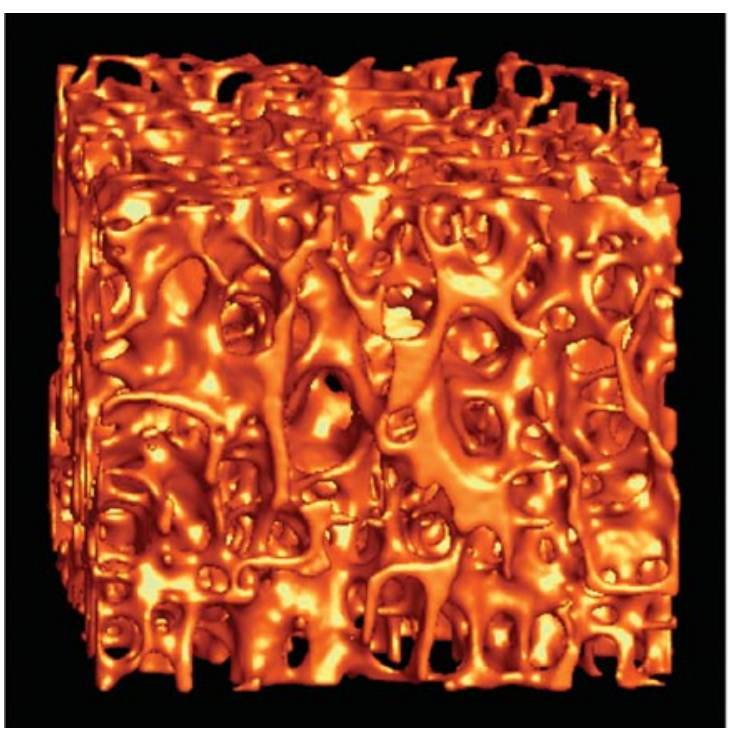

(b)

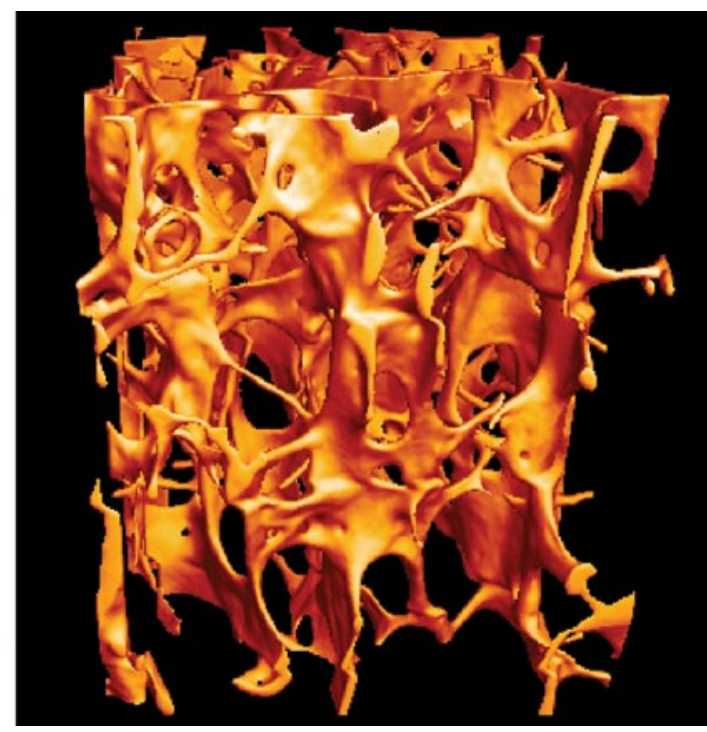

(a) A three-dimensional synchrotron computed-tomography image of a 4-millimeter-cube of trabecular bone from the vertebra interior of a 30-year-old female shows bone of normal density and architecture. A significant number of trabeculae and platelike structures are aligned in the load-bearing direction. (b) A similar image of a 63-year-old male shows a markedly different bone architecture, with fewer trabeculae and platelike structures. In addition, more of the trabeculae are shaped like slender rods. 
themselves, to destabilize the trabecular bone lattice under the right conditions." The team discovered that in aged bone, 60 percent of the trabeculae are subject to inelastic buckling when these pits or flaws are present in the bone.

"Several factors are at work here," says Kinney. "Bone loss makes the trabeculae longer and more slender. In addition, turnover introduces physical defects, in terms of resorption pits." The antiresorptive agents used to combat osteoporosis reduce this pitting and provide extra time to heal these defects. This aspect of bone turnover may be important to the overall understanding of fragile bones.

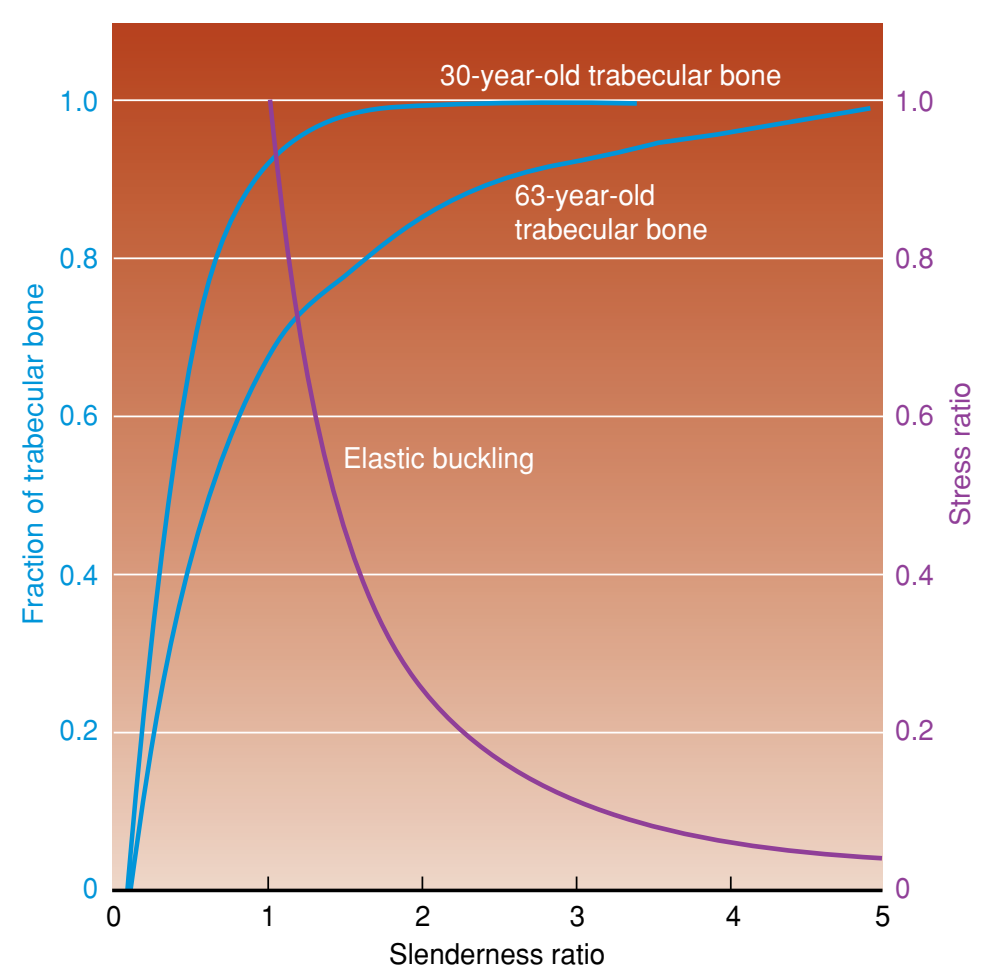

Comparisons of trabeculae from a 30-year-old woman and a 63-year-old man (blue curves) show that the older bone will break at a lower stress ratio than the younger bone. In this graph, stress is measured as the ratio of elastic buckling stress to tissue yield stress and will always be less than or equal to one. Elastic buckling (purple curve) is shown as a cumulative plot that compares the fraction of trabecular elements having a slenderness ratio that is less than or equal to the slenderness ratio on the horizontal axis.

\section{Improved Understanding of Bone Structure}

Kinney and his colleagues in Livermore's Mechanical Engineering Department are examining bone structure and failure from all angles to improve their understanding of osteoporosis and its role in bone fracture. "Once we understand the processes involved, we can better address the problem," says Kinney. "Today, drugs are available to control bone loss and to add bone mass. These drugs reduce fractures, but they also reduce bone turnover. We need to determine if there are negative implications to reducing bone turnover in the long run. Our research in dentin, funded by a grant from the National Institutes of Health, shows that age-related embrittlement can occur in the absence of turnover." Thus, stopping bone turnover may have a downside.

"We've been looking at changes in bone at the macro- and microscales. Now, we must examine the response of bone at the molecular levels. We are piecing it all together, little by little. Someday, I'm confident, we'll have the entire picture before us." - Ann Parker

Key Words: bone density, bone fracture, bone structure, buckling, NIKE3D, osteoporosis, trabecular bone. For further information contact John Kinney (925) 422-6669
(kinney3@IInl.gov). 


\section{Fusion Targets on the Double}

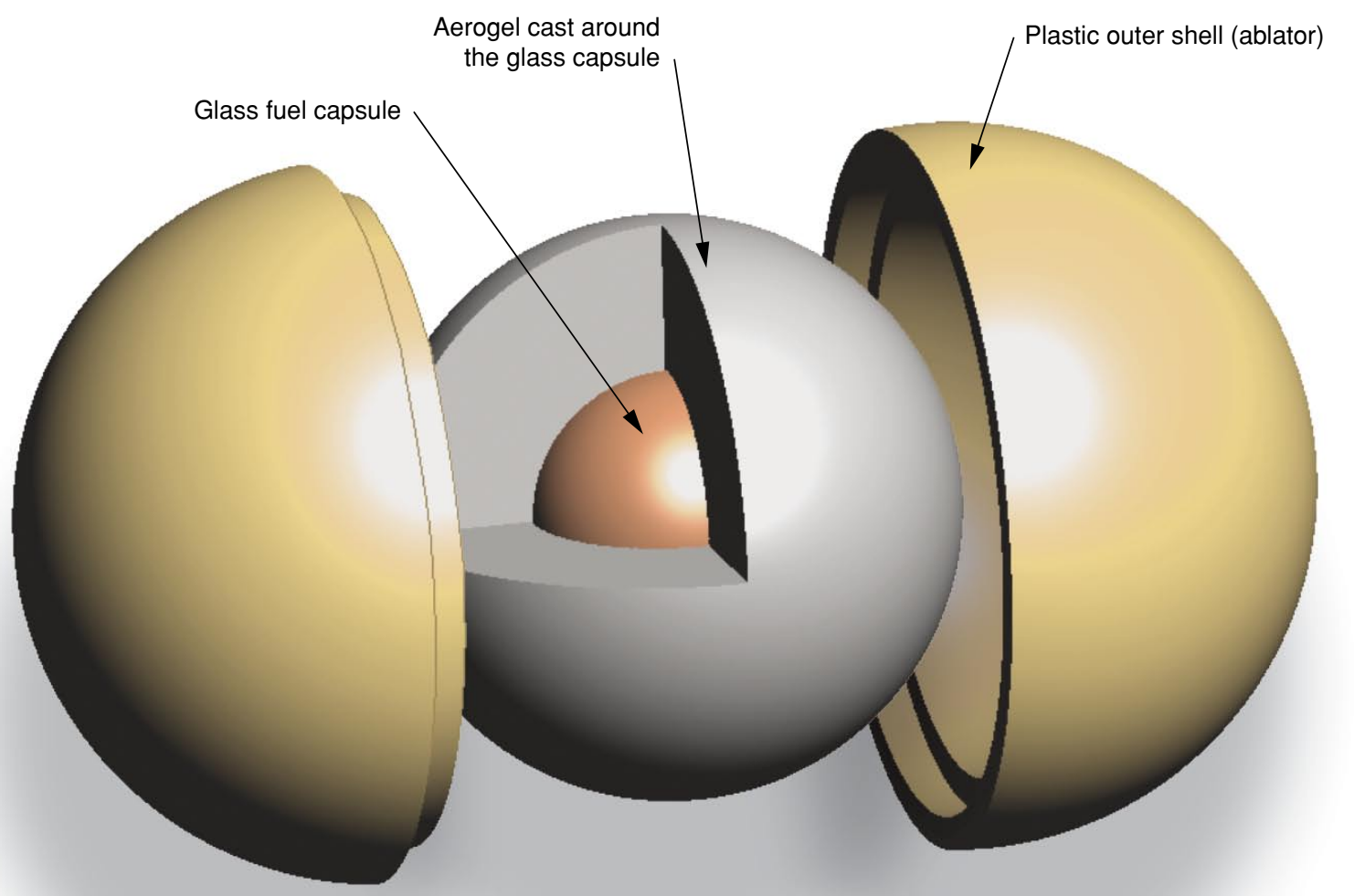

A double-shell target designed for fusion experiments consists of an inner capsule of fuel supported in aerogel and surrounded by a plastic outer shell (ablator).

MAGINE manufacturing an object that ends up being the size

of a dust mite. Nearly invisible to the naked eye when complete, it must be carefully machined and assembled and then precisely measured and inspected. Engineering experts at Lawrence Livermore have developed new tools and imaging methods that can do just that, meeting all fabrication requirements.

The dust-mite-size objects are spherical, double-shell targets that in August were blasted by x rays created on the OMEGA Laser at the University of Rochester's Laboratory for Laser Energetics. These and future experiments are designed to test how perfectly the targets implode. In 2010, such targets will face the enormous energy density of the National Ignition Facility's (NIF's) 192 beams. Achieving controlled thermonuclear ignition is one of the goals for NIF, and these targets are a critical aspect of successfully reaching that goal.

When $\mathrm{x}$ rays generated by a laser hit a double-shell target, the outer shell (ablator) absorbs the $\mathrm{x}$ rays, implodes, and collides with a smaller inner shell that contains a fuel of deuterium and tritium, isotopes of hydrogen. When conditions are just right, the deuterium and tritium atoms fuse into helium and release high-energy neutrons. Laser scientists have been investigating double-shell targets for fusion experiments since the 1980s. Calculations and models show that these targets can reach ignition conditions-tens of millions of degrees and a billion atmospheres of pressure-more easily than single-shell targets.

\section{New Tools for High Precision}

Double-shell targets for fusion experiments have a plastic ablator shell made of polystyrene doped with bromine. Inside that shell is a layer of silica dioxide aerogel, one of the lowest density materials in the world. The aerogel envelopes a tiny glass fuel capsule at the center. The fuel capsule must be precisely centered in the target - that is, the target must be concentric — and the shells must be as smooth as possible. When the ablator shell implodes, stability is crucial. Hydrodynamic instabilities near the fuel will reduce its ability to achieve ignition conditions.

Physicists who design laser experiments have known for some time what they want double-shell targets to look like. 
"The challenge has been to successfully fabricate them," says mechanical engineer Matthew Bono, leader of the Livermore manufacturing effort, which is part of the Target Technology Team. Bono's team has developed tools that allow an entirely new method of fabricating double-shell targets to eliminate defects. With this method, the team can achieve a higher level of concentricity and precision than was possible with past techniques.

Previously, a double-shell target was fabricated by placing a glass capsule of fuel between two hemispherical shells of aerogel. The fuel capsule was properly concentric within the aerogel, but $\mathrm{x}$-ray images revealed a void along the seam between the two aerogel hemispheres.

Now, aerogel is cast around the fuel capsule, using a process developed by the Livermore aerogel group, led by Joe Satcher. Chemist John Poco devised a method in which the aerogel sol is poured into a cubic mold until half full. When the sol begins to gel, the glass capsule is placed in the center, and more sol is added. Finally, all solvent is removed using a fast, supercritical extraction process that is much like taking water out of Jello. The result is a seamless cube about 1 centimeter square.

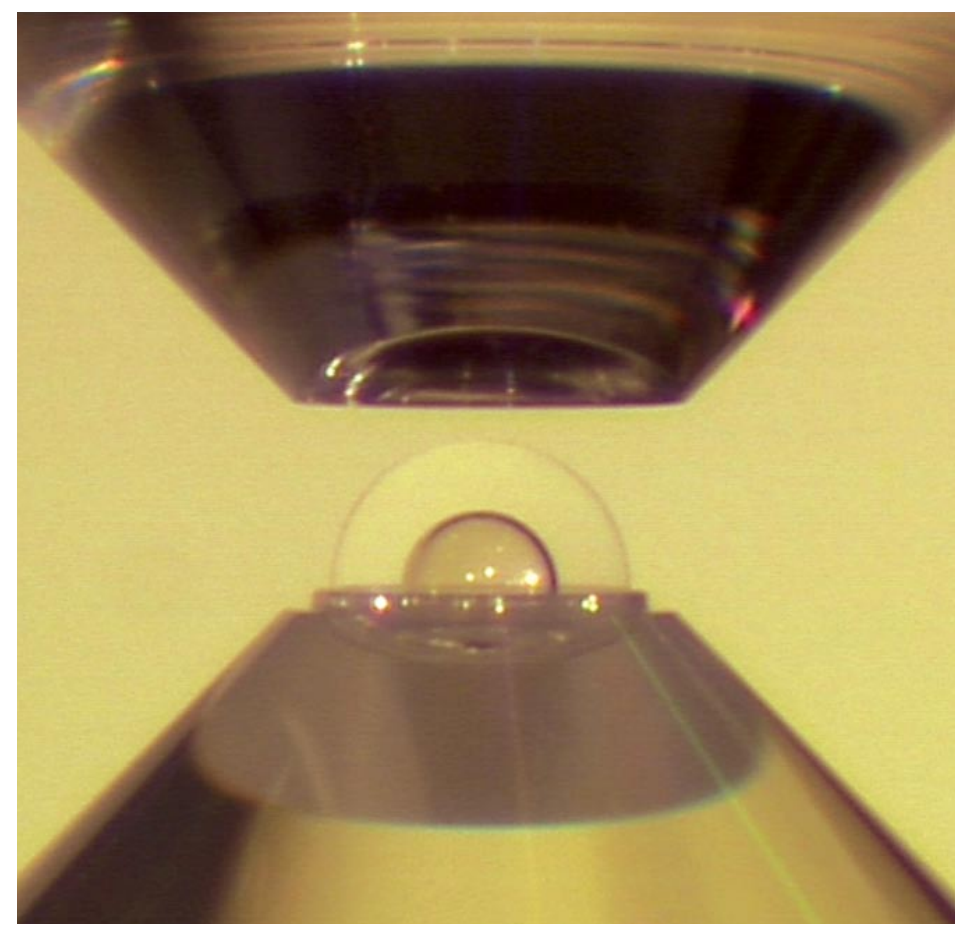

$\sim 440$ micrometers

During target assembly, the aerogel sphere is placed between the two halves of the ablator. Then the outer surface of the ablator is machined.
The cube of aerogel must then be made spherical and concentric around the fuel capsule, with a finished thickness of just over 100 micrometers - the width of a human hair. As in similar manufacturing processes, the material is machined. But how does one machine a material that is almost as light as air? Very, very carefully.

The first challenge is to mount the cube on the center of a diamond-turning machine's spindle, precisely symmetrical to the spindle's axis. Once the cube is properly mounted, it is roughmachined to dispose of the excess outer portions of aerogel. Fine adjustments are made prior to final machining, so that the aerogel and embedded capsule are concentric to a tolerance of less than 2 micrometers.

In most manufacturing settings, engineers use probes and other metrology tools to ensure that the finished product meets the required specifications. The products' dimensions, materials, and other properties are measured at various stages of the manufacturing process. The same is done for most millimeter-size laser targets made at Livermore. However, for these double-shell targets, existing metrology tools were not adequate, so new ones had to be invented.

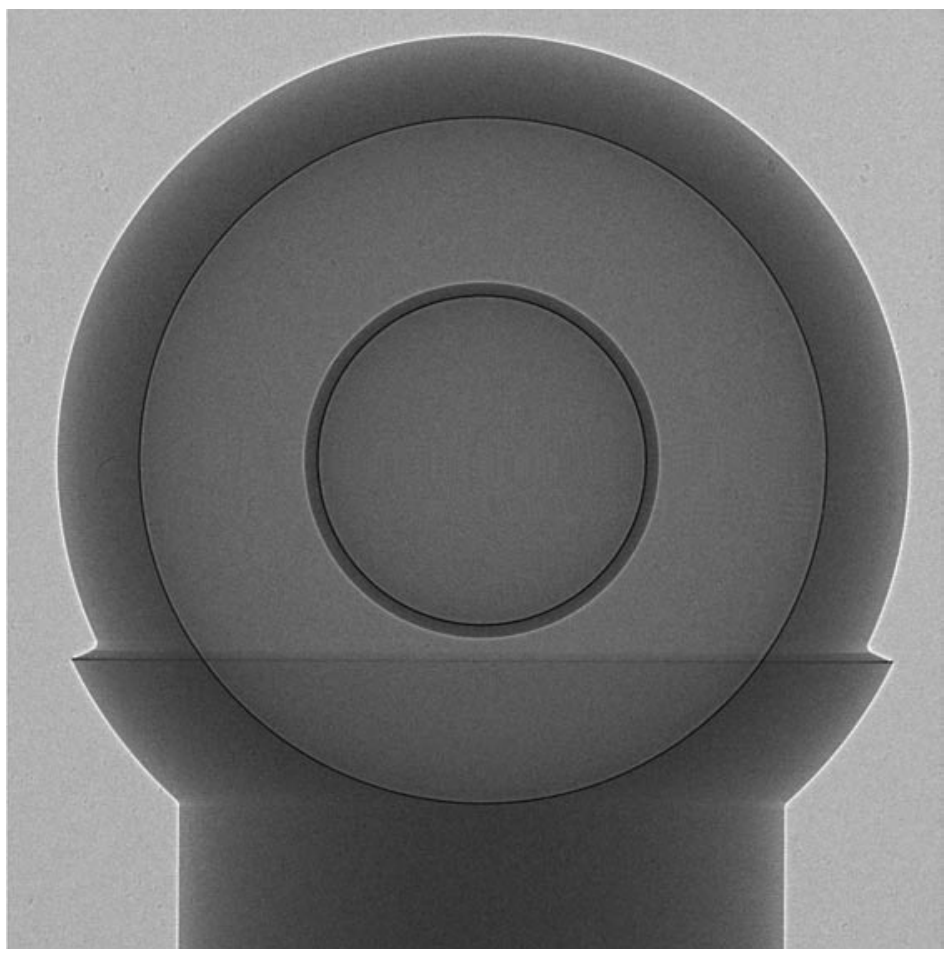

Radiograph of a double-shell target in fabrication reveals no flaws and shows that it meets or exceeds all specifications. The lower portion of the outer target shell has yet to be completely machined. 
The final thickness of the ablator shell is 53 micrometers. The total tolerance during machining is just 0.5 micrometer, or 500 nanometers. "That's just 250 nanometers of tolerance for each half of the ablator shell," notes Bono. "In a manufacturing environment, those tolerances are extremely difficult to achieve."

Bono's team developed a tool holder that can precisely position the diamond-cutting tool on the machining table. The cutting edge is centered to within 100 nanometers of the rotary table's axis of rotation-1/1,000th of a human hair's width. The team also designed an imaging system that acts as a measuring microscope. The system's camera is moved with respect to the aerogel workpiece, measuring the workpiece to ensure the radial and axial dimensions are always the same.

After the aerogel sphere is machined, the team starts work on the plastic ablator shell, which is fabricated in two halves. The inner surfaces of the two hemispheres are machined, including a step joint with a gap of 0.1 to 0.2 micrometer around the outer edge, where adhesive will later be applied. Bono's team uses a method of machining ablator components that compensates for the submicrometer thermal drift of the machine tool.

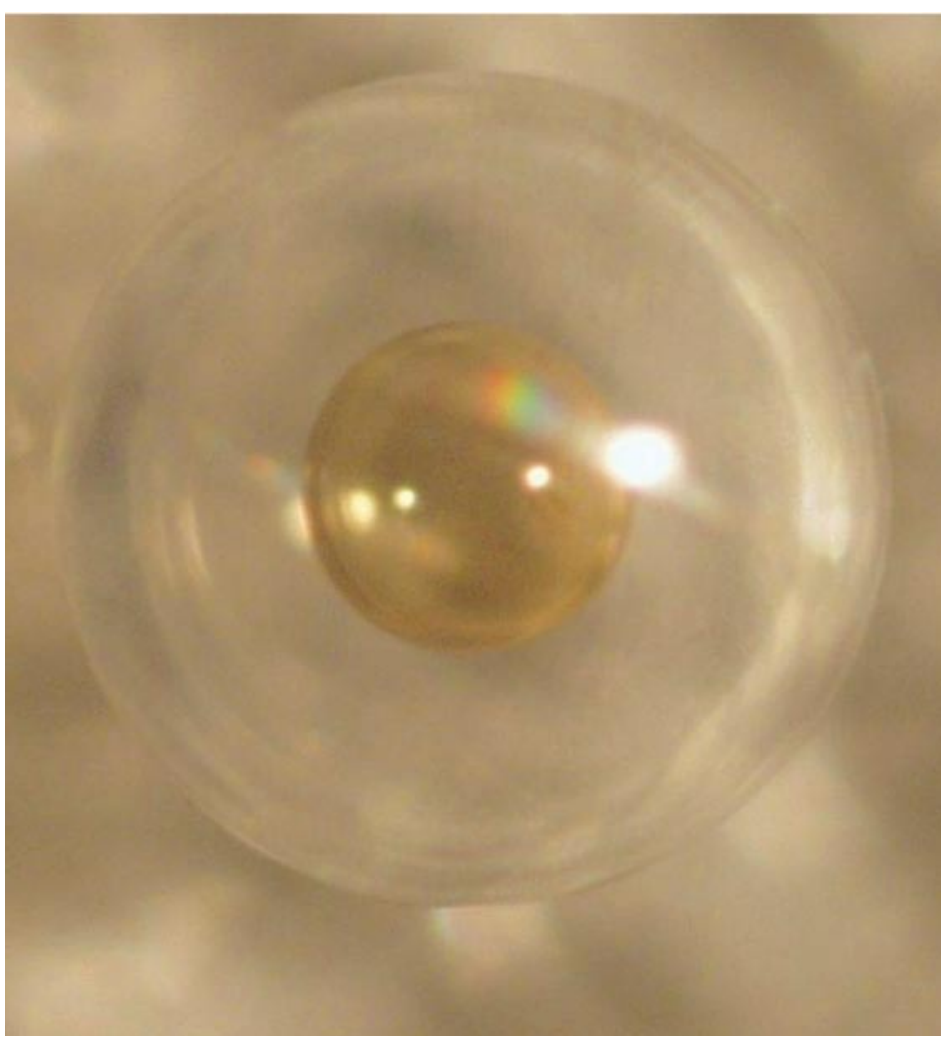

A finished double-shell target is just 0.5 millimeter in diameter.
The aerogel sphere is encased within the two halves of the ablator. Then the tiniest drop of adhesive is applied with a hair to a spot on the joint. The glue wicks around the seam, filling the gap completely and sealing the target.

\section{Perfect Scores in the Final Exam}

But the target is still not finished. A detailed examination is essential to ensure that it meets specifications. The target is examined using several $\mathrm{x}$-ray imaging systems, each with a different resolution and field of view. Radiographs show that after assembly, the uniformity of the ablator, specified to be within 1 micrometer, meets this specification. The shells, which are specified to be concentric to less than 3 micrometers, are concentric to less than 1.4 micrometers with no visible voids.

Finally, the outer surface of the ablator is diamond-turned to form a sphere. The entire process - from the creation of the aerogel cube to the finished target - takes several weeks of painstaking work. The result is a miniscule fusion target that is as symmetrical as can be manufactured today.

-Katie Walter

Key Words: ablator, aerogel, concentric tolerance, diamond turning, double-shell target, fusion experiment, submicrometer machining.

For further information contact Matthew Bono (925) 422-5883 (bono1@IInl.gov). 
Continued from p. 2

Earlier research by the same team indicated that male reproductive ability gradually worsens with age, as sperm counts decline and sperm lose mobility. In the current study, the researchers analyzed DNA damage, chromosomal abnormalities, and gene mutations in semen samples from the same subjects97 healthy, nonsmoking Livermore employees and retirees between 22 and 80 years old. The researchers found that sperm mobility showed a high correlation with DNA fragmentation, which is associated with increased risk of infertility and a reduced probability of fathering a successful pregnancy.

"This study shows that men who wait until they're older to have children are not only risking difficulties conceiving, they could also be increasing the risk of having children with genetic problems," says co-lead author Andrew Wyrobek of Livermore. The study appeared in the June 9, 2006, online edition of the Proceedings of the National Academy of Sciences.

\section{Contact: Andrew Wyrobek (925) 422-6296 (wyrobek1@IInl.gov).}

\section{Ancient galaxy cluster could shed light on dark matter}

Astronomers announced the discovery of the most distant cluster of galaxies ever found. The cluster may also be the most massive one yet seen at such an early era in the universe. Almost 10 billion light years from Earth, the cluster contains hundreds of galaxies surrounded by superheated, $\mathrm{x}$-ray-emitting gases. The X-Ray Multi Mirror (XMM) Cluster Survey team used observations from the European XMM-Newton satellite to discover the cluster. They determined its distance using the 10-meter W. M. Keck telescope in Hawaii.

The total mass of the cluster is enough to contain 500 trillion stars comparable in mass to our Sun. That's a surprising stellar mass for a galaxy cluster to have achieved at such an early era in the evolution of the universe, according to lead researcher Adam Stanford, a research scientist at Livermore and the University of California at Davis. Most of the mass is thought to be dark matter, a mysterious, invisible form of matter that dominates the mass of all galaxies in the universe. The team presented its findings at the 208th American Astronomical Society Meeting held June 4-8, 2006, in Calgary, Alberta, Canada.

Contact: Adam Stanford (925) 423-6013 (stanford3@IInl.gov).

\section{NNSA announces new mark for BlueGene/L}

The Department of Energy's National Nuclear Security Administration (NNSA) and IBM announced on June 22, 2006, that Livermore's BlueGene/L supercomputer has achieved a new mark. The world record for a scientific application was set by achieving a sustained performance of 207.3 trillion floatingpoint operations per second (teraflops) on the Qbox computer code. Ranked the world's fastest supercomputer by the Top 500 organization, BlueGene/ $\mathrm{L}$ is used to conduct materials science simulations for NNSA's Advanced Simulation and Computing (ASC) Program. The computer simulation capabilities developed by the ASC Program provide analyses that NNSA needs to keep the nuclear weapons stockpile safe, secure, and reliable.

Qbox is a first-principles molecular dynamics (FPMD) code, designed to predict the properties of metals under extreme temperatures and pressures. FPMD codes are used for complex simulations at the atomic level in a number of scientific areas, including metallurgy, solid-state physics, chemistry, biology, and nanotechnology. The "Q" in Qbox is for "quantum," a reference to the quantum mechanical descriptions of electrons. The ability to accurately model changes to the electronic structure of atoms distinguishes FPMD codes from classical molecular dynamics codes.

The three-dimensional FPMD code was run on BlueGene/L to study how molybdenum atoms behave under pressure. The simulation represents one of only a handful of "predictive science" simulations successfully modeling 1,000 atoms. Although classical molecular dynamics calculations are frequently run with billions of atoms, routine quantum runs, which are both very complex and accurate, have been restricted to about 50 atoms until now.

Contact: Mark Seager (925) 423-3141 (seager1@IInl.gov). 


\section{Patents}

\section{Graded Zooming \\ Douglas R. Coffland \\ U.S. Patent $7,035,479$ B2}

April 25, 2006

This system, which includes a camera connected to a computer, increases the far-field resolution of video or still-frame images while maintaining full coverage in the near field. The computer applies a specific zooming-scale factor to each line of pixels. Then it continuously increases the scaling factor of the lines from the bottom to the top, thus capturing the scene in the near field and maintaining the scene's resolution in the far field.

High Density Polymer-Based Integrated Electrode Array Mariam N. Maghribi, Peter A. Krulevitch, James Courtney Davidson, Julie K. Hamilton

U.S. Patent 7,035,692 B2

April 25, 2006

This high-density polymer-based integrated electrode apparatus has a central electrode body with multiple arms extending from it. The central electrode body and its arms are composed of a silicone material with metal features that serve as electronic circuits.

System and Method for Characterizing Voiced Excitations of Speech and Acoustic Signals, Removing Acoustic Noise from Speech, and Synthesizing Speech

Greg C. Burnett, John F. Holzrichter, Lawrence C. Ng

U.S. Patent 7,035,795 B2

April 25, 2006

The present invention is a system and method for characterizing human (or animate) voiced excitation functions and acoustic signals, removing unwanted acoustic noise that often occurs when a speaker uses a microphone in common environments, and synthesizing personalized or modified human (or other animate) speech on command from a controller. A low-power electromagnetic (EM) sensor is used to detect the motions of windpipe tissues in the glottal region of the human speech system before, during, and after speech is produced by a user. A voiced excitation function can be derived from these tissue motion measurements. In addition, the excitation function provides speech production information to enhance noise removal and allows accurate speech-transfer functions to be obtained. Previously stored excitation and transfer functions can be used to synthesize personalized or modified human speech. The EM sensor and acoustic microphone systems can be configured to enhance noise cancellation and measure multiple articulators.

Pin-Deposition of Conductive Inks for Microelectrodes and Contact via Filling

J. Courtney Davidson, Peter A. Krulevitch, Mariam N. Maghribi, Julie K. Hamilton, William J. Benett, Armando R. Tovar

U.S. Patent 7,036,220 B2

May 2, 2006

In this method of metallization for an integrated microsystem, small aliquots of a conductive material are taken up and applied on a substrate to produce a circuit component.
High Power 938 Nanometer Fiber Laser and Amplifier Jay W. Dawson, Zhi Ming Liao, Raymond J. Beach, Alexander D. Drobshoff, Stephen A. Payne, Deanna M. Pennington, Wolfgang Hackenberg, Domenico Bonaccini Calia, Luke Taylor

U.S. Patent $7,038,844$ B2

May 2, 2006

This amplifier includes a length of silica optical fiber that has a neodymium-doped core and two claddings, each with a succeedingly lower refractive index. The diameter of the first cladding is less than 10 times that of the core. The doping concentration of the neodymium is chosen so that the signal absorption for 816-nanometer light traveling within the core is less than 15 decibels per meter above the other fiber losses. The amplifier is optically pumped with one laser into the fiber core and with another laser into the first cladding.

\section{Staged Combustion with Piston Engine and Turbine Engine High Supercharger \\ Larry E. Fischer, Brian L. Anderson, Kevin C. O’Brien \\ U.S. Patent 7,040,094 B2}

May 9, 2006

A combustion engine method and system provides increased fuel efficiency and reduces pollution exhaust emissions by burning fuel in a two-stage combustion system. Fuel is combusted in a first-stage piston engine producing piston engine exhaust gases. Fuel contained in these gases is then combusted in a second-stage turbine engine. Turbine engine exhaust gases are then used to supercharge the piston engine.

Chemical Amplification Based on Fluid Partitioning

Brian L. Anderson, Billy W. Colston, Jr., Chris Elkin

U.S. Patent 7,041,481 B2

May 9, 2006

A system for nucleic acid amplification of a sample that involves partitioning the sample into sections and performing polymerase chain reaction (PCR) on the sections. Another embodiment of the invention provides a system for nucleic acid amplification and detection of a sample by partitioning the sample into sections, performing PCR on the sections, and detecting and analyzing the sections.

\section{Compact Reflective Imaging Spectrometer Utilizing Immersed Gratings} Michael P. Chrisp

U.S. Patent 7,041,979 B2

May 9, 2006

This compact imaging spectrometer has an entrance slit for directing light, a first mirror for receiving and reflecting the light, an immersive diffraction grating for diffracting the light, a second mirror for focusing the light, and a detector array for receiving the focused light. The compact imaging spectrometer can be used as a remote-sensing imaging spectrometer when size and weight are important.

\section{Ceramic Inspection System}

Michael E. Werve

U.S. Patent $7,043,998$ B2

May 16, 2006

This system can be used to inspect a ceramic component. The ceramic component is positioned on a first rotary table, which rotates the component. Light is directed toward the first rotary table and the rotating ceramic component. A detector is located on a second rotary table. The 
second table is connected to the first rotary table and the rotating ceramic component. The second rotary table moves the detector at an angle to the first rotary table and the rotating component.

\section{Solid-Phase Microextraction Fiber Cleaning and Conditioning Apparatus and Method}

Armando Alcaraz, Michael H. Wiefel

U.S. Patent 7,047,661 B2

May 23, 2006

The solid-phase microextraction (SPME) fiber cleaning and conditioning apparatus has an elongated heating chamber with first and second opposite ends. The first end can receive an SPME fiber portion of an SPME device, and the second (send) end is a fluid outlet. A heater is used to heat the chamber and heat-treat an inserted SPME fiber. Contaminants and other particles are agitated, desorbed, and purged from the inserted SPME fiber by flowing a fluid through the chamber from the first end to the second end, away from the SPME device. In addition, turbulence may be produced in the flow at a location adjacent the first end to enhance agitation, desorption, and purging. A holder may also extend from the first end to support the SPME device in a substantially horizontal orientation when the SPME fiber is positioned in the chamber.

Method of Defining Features on Materials with a Femtosecond Laser Edward Victor Roos, Franklin Roeske, Ronald S. Lee, Jerry J. Benterou U.S. Patent 7,049,543 B2

May 23, 2006

In this method, laser ablation is used to define metals or dielectric films on the surface of a wafer, printed circuit board, or hybrid substrate. Highenergy, ultrashort pulses of laser light are used to manufacture electronic circuits or electromechanical assemblies without affecting the material adjacent to the ablation zone.

High-Efficiency Spectral Purity Filter for EUV Lithography

Henry N. Chapman

U.S. Patent 7,050,237 B2

May 23, 2006

An asymmetric-cut multilayer diffracts extreme ultraviolet (EUV) light. A multilayer cut at an angle has the same properties as a blazed grating and has been demonstrated to have near-perfect performance. Rather than nanofabricating a grating structure with imperfections no greater than several tens of nanometers, a thick multilayer is grown on a substrate and then cut at an inclined angle using coarse and inexpensive methods.
Effective grating periods can be produced that are 10 to 100 times smaller than those produced today, and the diffraction efficiency of these asymmetric multilayers is higher than conventional gratings. Using an asymmetric multilayer as a spectral purity filter does not require that the design of an EUV optical system be modified, unlike the proposed use of blazed gratings for such systems.

Durable Silver Thin Film Coating for Diffraction Gratings

Jesse D. Wolfe, Jerald A. Britten, Aleksey M. Komashko

U.S. Patent 7,054,065 B2

May 30, 2006

A durable silver thin-film coating on a nonplanar optical element has been developed to replace gold as a material for fabricating such devices. An optical element with this coating is more efficient and resistant to tarnishing. It can also be easily stripped and redeposited without modifying the underlying grating structure. The element improves the throughput and power loading of short-pulse compressor designs for ultrafast laser systems and can be used in a variety of optical and spectrophotometric systems, particularly high-end spectrometers that require maximized efficiency.

Synthesis and Purification of 1,3,5-Triamino-2,4,6-Trinitrobenzene (TATB)

Alexander R. Mitchell, Michael D. Coburn, Gregory S. Lee, Robert D. Schmidt, Phillip F. Pagoria, Peter C. Hsu

U.S. Patent 7,057,072 B2

June 6, 2006

A method to convert surplus nitroarene explosives (picric acid, ammonium picrate) into TATB is described. The process has three major steps: conversion of picric acid and ammonium picrate to picramide, conversion of picramide to TATB through vicarious nucleophilic substitution of hydrogen chemistry, and purification of TATB.

Synthesis of Trinitrophloroglucinol and Triaminotrinitrobenzene (TATB) Alexander R. Mitchell, Michael D. Coburn, Gregory S. Lee, Robert D. Schmidt, Phillip F. Pagoria, Peter C. Hsu

U.S. Patent 7,057,073 B2

June 6, 2006

This method can be used to convert surplus nitroarene explosives into trinitrophloroglucinol and triaminotrinitrobenzene (TATB). Picric acid is directly aminated to diaminopicric acid, which is converted to trinitrophloroglucinol and triaminotrinitrobenzene.

\section{Awards}

The National Nuclear Security Administration's (NNSA's) Advanced Simulation and Computing (ASC) Program at Lawrence Livermore was named a Computerworld Honors Program laureate for its role in the development of the world's fastest supercomputer, BlueGene/L.

The ASC Program was a finalist in the Science category of the Computerworld Honors awards, which recognize "contributions that organizations and people have made for the betterment of society through the exceptional - if not heroic - use of information technology." ASC was nominated for the award by IBM.

Dona Crawford, associate director for Livermore's Computation Directorate, accepted a laureate medal and plaque on behalf of the ASC Program in a recent ceremony in Washington, DC. Dimitri Kusnezov, director of NNSA's ASC Program, also attended the ceremony. 


\section{Re-creating the 1906 San Francisco Earthquake}

Lawrence Livermore scientists participated in a two-year earthquake study organized by the U.S. Geological Survey. The study's goals were to simulate ground motions that were generated by the 1906 San Francisco earthquake, compare the results with observations and seismograms recorded at the time, and examine future earthquake scenarios throughout the San Francisco Bay Area. The Livermore team used several codes that are optimized to run on massively parallel supercomputers. The codes incorporate three-dimensional information about the propagation of seismic waves. The simulation codes are helping San Francisco Bay Area officials plan for future earthquakes.

\section{Contact:}

Arthur J. Rodgers, Jr. (925) 423-5018 (rodgers7@IInl.gov).

\section{Decoding the Origin of a Bioagent}

The 2001 attacks with anthrax in mailed letters galvanized the nation's security community to strengthen the emerging area of microbial forensics, which attempts to trace biological agents to their source. Scientists from Lawrence Livermore are involved in the Federal Bureau of Investigation's (FBI's) Scientific Working Group for Forensic Analysis of Microbial Evidence, formed in 2002 to guide the development of new microbial forensic techniques. Laboratory researchers are developing new genetic typing techniques for quickly identifying strains of bacterial species and biological toxins. They are also using atomic force microscopy and nanometer-scale secondary-ion mass spectrometry to correlate spore microstructures to formulation methods. In addition, Livermore researchers are assisting the FBI and other federal agencies by developing methods for collecting and extracting biological threat agents and their DNA from crime scenes and forensic samples.

\section{Contact:}

Steve Velsko (925) 423-0191 (velsko2@IInl.gov).

\section{Livermore tainifirs SaVtin RPD 100 Awaris}

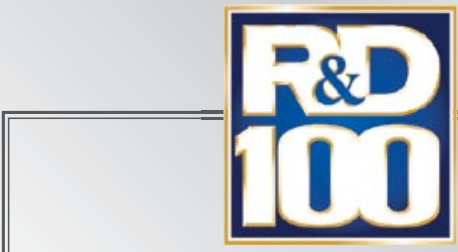

Presented to

LAWRENCE LIVERMORE NATIONAL LABORATORY

Selected by R\&D Magazine as One of the 100 Most Technologically Significant New Products of the Year

\section{6}

Laboratory researchers had a banner year in $R \& D$ Magazine's annual competition for the 100 most significant technological products and processes.

\section{Also in October}

- Livermore engineers invent and fabricate various micro- and nanodevices for national security.

- A multiagency team led by Lawrence Livermore and Sandia national laboratories is developing restoration procedures to decontaminate a major airport after an attack with biological weapons. 
University of California

Science \& Technology Review

NONPROFIT ORG.

Lawrence Livermore National Laboratory

P.O. Box 808, L-664

Livermore, California 94551 